\title{
Systems Microbiology and Engineering of Aerobic-Anaerobic Ammonium Oxidation
}

\author{
David G. Weissbrodt ${ }^{1,}{ }^{*}$, George F. Wells ${ }^{2}$, Michele Laureni ${ }^{1}$, Shelesh Agrawal ${ }^{3}$, \\ Ramesh Goel ${ }^{4}$, Giancarlo Russo ${ }^{5}$, Yujie Men ${ }^{6}$, David R. Johnson ${ }^{7}$, \\ Magnus Christensson ${ }^{8}$, Susanne Lackner ${ }^{3}$, Adriano Joss ${ }^{7}$, Jeppe Lund Nielsen ${ }^{9}$, \\ Helmut Bürgmann ${ }^{7}$ and Eberhard Morgenroth ${ }^{7,10}$
}

\author{
${ }^{1}$ Department of Biotechnology, Delft University of Technology, Delft, The Netherlands \\ ${ }^{2}$ Department of Civil and Environmental Engineering, Northwestern University, Evanston, IL, USA \\ ${ }^{3}$ Technische Universität Darmstadt, Institute IWAR, Chair of Wastewater Engineering, Darmstadt, Germany \\ ${ }^{4}$ Department of Civil and Environmental Engineering, The University of Utah, Salt Lake City, UT, USA \\ ${ }^{5}$ Functional Genomics Center, ETH Zürich and University of Zürich, Zürich, Switzerland \\ ${ }^{6}$ Department of Chemical and Environmental Engineering, University of California, Riverside, USA \\ ${ }^{7}$ Eawag, Swiss Federal Institute of Aquatic Science and Technology, Dübendorf, Switzerland \\ ${ }^{8}$ Veolia Water Technologies, AnoxKaldnes, Lund, Sweden \\ ${ }^{9}$ Department of Chemistry and Bioscience, Center for Microbial Communities, Aalborg University, Aalborg Denmark \\ ${ }^{10}$ Institute of Environmental Engineering, ETH Zürich, Zürich, Switzerland
}

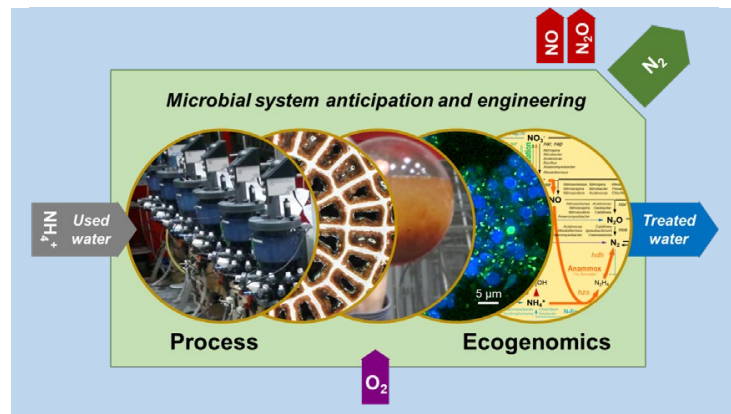

Partial nitritation and anammox (PN/A) is attractive for a complete chemolithoautotrophic removal of nitrogen from wastewater. Mixed-culture biotechnologies like PN/A rely on systemslevel understanding and management of complex microbial communities. "Process ecogenomics" is promoted to integrate community systems microbiology into process physical designs. Scientific elucidation of microbial and metabolic networks of microbiomes should provide readily assimilable information to engineer them. Systems microbiology delivers thorough insights on the balance of metabolic interactions in microbiomes that should then be managed by engineering of process conditions.
Abstract: Aerobic and anaerobic oxidations of ammonium are core biological processes driving the nitrogen cycle in natural and engineered microbial ecosystems. These conversions are tailored in mixed-culture biotechnology to propel partial nitritation and anammox (PN/A) for a complete chemolithoautotrophic removal of nitrogen from wastewater at low resource and energey expenditures. Good practices of microbiome science and engineering are needed to design microbial PN/A systems and translate them to a spectrum of wastewater environments. Inter-disciplinary investigations of systems microbiology and engineering are paramount to harness the microbial compositions and metabolic performance of complex microbiomes. We propose "process ecogenomics" as an integration ground to combine community systems microbiology and microbial systems engineering by establishing a synergy between the life and physical sciences. It drives a high-resolution analysis, engineering and management of microbial communities and their metabolic performance in mixed-culture systems. While addressing the key underpinnings of the science and engineering of aerobic-anaerobic ammonium oxidations, we advocate the need to formulate targeted research questions in order to elucidate and manage microbial ecosystems in wastewater environments. We propose a systems-level roadmap to investigate and functional engineer technical microbiomes like PN/A, via: (i) quantitative biotechnological measurement of stoichiometry and kinetics of nitrogen turnovers; (ii) genome-centric metagenomic fingerprinting of the microbiome; (ii) ecophysiological examination of the main metabolizing lineages; (iii) multi-omics elucidation of expressed metabolic functionalities across the microbial network; and (iv) translation of microbial and functional ecology principles into physical designs.

Keywords: Mixed-culture biotechnology; Microbial resource management; Microbial community engineering; Systems microbiology; Process ecogenomics; $\mathrm{Ni}$ tritation-anammox.

\section{Acronyms and abbreviations}

$A M O$ : anaerobic ammonium-oxidizing organism; anammox: anaerobic ammonium oxidation; $A N R A$ : assimilatory nitrite reduction to ammonia; $A O A$ : ammonium-oxidizing archaeum; $A O B$ : ammonium-oxidizing bacterium; $A O O$ : aerobic ammonium-oxidizing organism; $A S V$ : amplicon sequence variants; BNR: biological nutrient removal; Ca.: Candidatus; CLSM: confocal laser

\footnotetext{
* Correspondence: Prof. David Weissbrodt, Assistant Professor, TU Delft, TNW-BT-EBT, Building 58, van der Maasweg 9, NL-2629 HZ Delft, The Netherlands; Tel +31 15278 1482; e-mail: d.g.weissbrodt@tudelft.nl
} 
scanning microscopy; DNA: deoxyribonucleic acid; DNRA: dissimilatory nitrate reduction to ammonia; $D H O$ : heterotrophic denitrifying organism; EFM: epifluorescence microscopy; EPS: extracellular polymeric substances; FISH: fluorescence in situ hybridization; FLBA: fluorescence lectin-binding analysis; gDNA: genomic DNA; HRT: hydraulic retention time; $M A R$ : microautoradiography; $M C E$ : microbial community engineering; $m R N A$ : messenger RNA; NanoSIMS: nanoscale secondary ion mass spectrometry; $N-D A M O$ : nitrite-driven anaerobic methane oxidation; $N O O$ : nitrite-oxidizing organism; $O H O$ : ordinary heterotrophic organism; OTU: operational taxonomic unit; $P C R$ : polymerase chain reaction; $P N / A$ : partial nitritation and anammox; qFISH: quantitative FISH; $q P C R$ : quantitative real-time PCR; $R N A$ : ribonucleic acid; $r R N A$ : ribosomal RNA; $R T$ : reverse transcription; SIP: stable isotope probing; SRT: sludge retention time.

\section{Introduction}

The biotechnology of the nitrogen cycle ${ }^{1}$ is an attractive field under constant evolution and rediscovery 2 to promote sustainable solutions for wastewater treatment and environmental services ${ }^{3}$. Complex ecosystems like activated sludge remains a vast below ${ }^{4}$. Discoveries of new organismal functions promote new engineering designs ${ }^{5}$. Significant breakthroughs in microbiological science ${ }^{6}$, process engineering science ${ }^{7}$, and analytical bioscience ${ }^{8}$ have led to better understand and make use of metabolic interactions that govern nitrogen conversions. This microbial network comprises a diversity of lithoautotrophic, organoheterotrophic and nitrogen-fixing organisms that act in concert to metabolize nitrogen.

The completely autotrophic process of aerobic (i.e., nitrification) and anaerobic ammonium oxidation (anammox) is economically and technologically appealing to remove nitrogen from wastewater at low energetic and resource expenditures ${ }^{9-11}$. This open mixed-culture biotechnology is referred to as partial nitritation and anammox (PN/A) in engineering practice ${ }^{12,13}$. It is one masterpiece of environmental biotechnology.

\subsection{An established potential from microbial process discovery to engineering innovation}

PN/A developments started from the postulation for and discovery of novel chemolithoautotrophic microorganisms involved in anammox from natural ${ }^{14,15}$ and engineered settings ${ }^{16,17}$. Anammox is credited with massive transformations of nitrogen and production of about half of atmospheric dinitrogen ${ }^{18-21}$. Engineering efforts to metabolically combine guilds of anammox organisms (referred to as AMOs according to standardized notation by Corominas, et al. ${ }^{22}$ ) with their aerobic counterparts (AOOs) has driven the attractiveness of PN/A on the biological wastewater treatment market 7 .
Evolving concepts on the field of PN/A are illustrated by Fig. 1.

Full-scale PN/A systems are increasingly implemented to treat high loads of nitrogen from concentrated streams such as anaerobic digester centrates ("side streams" on flow-schemes of wastewater treatment plants, WWTPs), landfill leachates, livestock effluents, and source-separated urine 23-27. Current incentives target PN/A implementation for the direct treatment of diluted municipal wastewaters ("main streams") ${ }^{28-35}$. Success in this endeavor may constitute a major advance for the environmental engineering sector, while technological challenges still needs to get overcome. An efficient combination of several disciplines within environmental biotechnology is needed to this end 36.

\subsection{Managing PN/A processes under the scope of systems microbiology}

PN/A processes harbor high potential to improve the energy efficiency of WWTPs while achieving effective nitrogen removal ${ }^{7,37}$. Engineering ambitions and limitations have been formulated. Following promising start-up behavior, longer-term PN/A operations have been related to process instabilities and operational challenges ${ }^{23,38}$. Maintaining a reliable performance is not trivial ${ }^{39}$ since PN/A systems should rely on a coordinated activity and cross-feeding between AOO and AMO guilds 40. PN/A biosystem performance and instability should be elucidated on a continuum from process engineering to environmental biotechnology and systems microbiology. Systems-level investigations ${ }^{41}$ should bridge process boundaries (i.e., macro scale), bioaggregate properties (i.e., meso scale), and microbial communities (i.e., micro scale) from populations to their genomes and expressed metabolisms. 
1 Observing metabolic conversions at process level

Understanding deviations to nitrogen mass balance

2 Investigating microbial populations and metabolisms

- Prospecting for anaerobic ammonium oxidizing organisms

- Achieving a microbial syntrophy (aerobic-anaerobic)

\section{Engineering PN/A processes}

- Coupling partial nitritation and anammox (PN/A)

- Designing process configurations

- Investigating performance levels, reliability, and instabilities

- Transposing from sidestream to mainstream

4 Managing the bacterial resource using microbial ecology

- Managing the microbial resource

- Engineering microbial communities by ecological principles

\section{Developing a systems microbiology framework}

- Validating new-generation wet-lab \& dry-lab molecular methods

- Unravelling the PN/A microbiome (sidestream, mainstream)

- Triggering functional activation and validating ecophysiologies

\section{Integrating strategies of process ecogenomics}

Harnessing metabolic signatures to engineer microbial systems

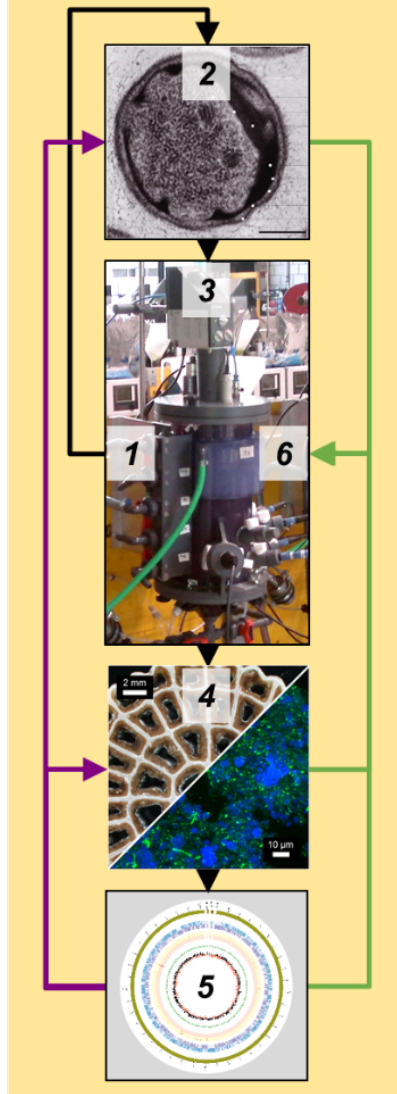

Figure 1. Evolution of the science of PN/A processes. It was launched by the observation at engineering level of substantial loss in nitrogen mass balances in nitrifying and denitrifying biofilm systems (1). Anammox populations and metabolisms are studied extensively at microbiology level in high-grade enrichments since then (2). This fundamental knowledge has then been transferred back to practice for in two-stage and single-stage technologies achieving a syntrophy of aerobic and anaerobic ammonium oxidizers (3). Principles of microbial ecology and microbial community engineering are required for a good practice of microbial resource management in PN/A systems, which display instabilities on the long run (4). Systems microbiology will allow to unravel and harness the phylogenetic, ecophysiology, and metabolic features that underlie the performance of the PN/A microbial system beyond the bioaggregate boundaries (5). The development of a "process ecogenomics" framework in the engineering context is key to bring engineers closer to their PN/A biosystem, and to transpose microbial community signatures and ecogenomics concepts into engineering (6). Images 2 and 5 were taken from Kuenen ${ }^{42}$, and Albertsen, et al. ${ }^{43}$, respectively.

Advances in sequencing and bioinformatics have driven the elucidation of this microbial "dark matter". Phylogenetic, genomic and metabolic signatures of complex natural and engineered microbiomes can be tackled with high throughput and resolution in a science frequently referred to as systems microbiology or "ecogenomics" ${ }^{44-48}$. Community systems microbiology ${ }^{49-51}$ can provide mechanistic insights on microbial selection, interaction and competition by unravelling the functional ecology of the PN/A microbiome.

Engineering microbiomes is like engineering a bridge. The design-build-test-learn (DBTL) cycle typically used in civil engineering has been translated to microbiomes ${ }^{52}$. Collaboration between process engineers, environmental biotechnologists and microbiologists is fundamental to advance
PN/A. Starting from early calls for synergies between microbial ecology, environmental microbiology, and environmental biotechnology ${ }^{53-55}$, we emphasize the need for close interaction and consensus building between the life and physical sciences.

A glossary is provided at the end of the article on terminologies and concepts. We therefore promote the integrative discipline of "process ecogenomics" for systems-level investigations, using PN/A as a guiding thread, to analyze, understand, engineer and control technical microbial communities and their distributed metabolic performance. 


\section{Engineering the performance of the micro- bial ecosystem}

\subsection{PN/A biotechnology: managing scales beyond process variations}

Process performance and variabilities originate from multi-scale interactions ${ }^{41,56}$ (Fig. 2).

At macro scale, impacts of process configurations (e.g., two-stage or single-stage), operational conditions, and environmental perturbations on PN/A remain far from being fully understood and solved $23,38,57,58$. Applied research is actively involved to optimize sidestream installations, while new applications are investigated to implement PN/A along with variations in wastewater composition, loads, and temperature at mainstream ${ }^{59-62}$.

At meso scale, PN/A has been achieved using various biomass morphotypes such as flocs, granules, biofilms and hybrid biofilms-flocs combinations 33,63-67. Suspended-growth (i.e., flocs) and attachedgrowth (i.e., biofilms) regimes exhibit different performances mostly relying on substrate diffusion 68 , while no consensus has converged on process benefits. Flocculent sludge displays interesting PN/A activity with stable baseline conversions ${ }^{69}$. However, flocs do not offer a durable and resilient solution to maintain a substantial guild of active AMOs ${ }^{38}$. Physical separation using, e.g., hydrocyclones ${ }^{70}$ prevent the wash-out of these slow-growing organisms that exhibit doubling times between 2-30 $\mathrm{d}^{71,72}$ and that assemble into compact microcolonies forming dense granular aggregates. Biofilm reactors intensify volumetric rates and possibly achieve higher robustness ${ }^{68,73}$. In biofilm systems, the presence of a floc fraction as low as 5\% of the total biomass affects the nitrification and PN/A performances ${ }^{74,75}$. True hybrid biofilm-floc systems such as integrated fixed-film activated sludge (IFAS) processes benefit from intrinsic features of both biofilms and a substantial amount of flocculent sludge ${ }^{64}$.

At micro scale, engineering the PN/A mixed culture is required to select and activate the microorganisms toward reliable performances. PN/A traditionally leads - while neglecting anabolism and decay - to estimated savings of $60 \%$ in aeration energy, $65 \%$ in alkalinity, $100 \%$ in organic requirement, and $95 \%$ in surplus sludge production ${ }^{76,77}$, while favorably uncoupling nitrogen from carbon removal ${ }^{77}$. An efficient management of the microbial resource should drive the syntrophy between AOOs and AMOs ${ }^{40,78-80}$, while preventing their outcompetition by autotrophic nitrite-oxidizing organisms (NOOs) and denitrifying heterotrophic organisms (DHOs) ${ }^{81-83}$. A balance of interactive microbial niches is aimed along gradients of solutes inside bioaggregates ${ }^{84,85}$. Localizations of populations differs according to physiologies and metabolisms, which has been rationalized in mathematical models using stoichiometry and kinetics, including yields, growth rates, substrate affinities and inhibition effects ${ }^{75,86}$. Their micro-scale interactions are strongly impacted by morphotypes involved in the process, but do reversely determine important meso-scale properties of bioaggregates 87. Maintaining AMOs in suspended flocs is more challenging in the long term ${ }^{38,88}$. In hybrid systems, AOOs mostly occupy the floc fractions where they experience a more uniform distribution of solute concentrations and readily access the oxygen dissolved in the bulk liquid phase $59,64,71,72,89,90$. AOOs and AMOs can be maintained inside the architectures of biofilms ${ }^{63}$ and granules ${ }^{58}$. Attached growth prevents the unfavorable washout of AMOs. Diffusional limitations in biofilms allow them to adapt to oxygen-depleted microenvironments. AMOs benefit from larger anoxic zones in biofilms. NOOs unfavorably populate biofilms when competing for nitrite, while their beneficial wash-out is more simply realized from flocs ${ }^{67}$.

Bacterial population segregation in PN/A systems is illustrated in Fig. 3. Amplicon sequencing analysis of biofilm and floc fractions of sidestream and mainstream processes highlighted that AMOs principally populate the biofilms of both types of systems while AOOs and NOOs are mainly present in the flocs. DHOs are present in both flocs and biofilms, with a more balanced partitioning between the two types of aggregates under mainstream conditions. These predominant metabolizing guilds are accompanied by a diversity of populations that make up to more than $60 \%$ of the PN/A community, but whose functions remains poorly investigated ${ }^{91}$. Many are supposed to thrive on metabolites and endogenous products released within the microbial ecosystem. Populations of the family of Saprospiraceae hydrolyze complex carbonaceous substrates making their presence in the floc fraction of sidestream systems (whose influent contain a 
substantial fraction of recalcitrant organic matter remaining after anaerobic digestion) rational. Populations within Gemmatinonadaceae are slowgrowing anaerobic-aerobic organisms with traits resembling polyphosphate-accumulating organisms (PAOs) ${ }^{92}$. Their higher relative abundance at mainstream can result from the loads of orthophosphate present in municipal wastewater, and might be of interest in the perspective of coupling biological phosphorus removal to PN/A ${ }^{93}$.
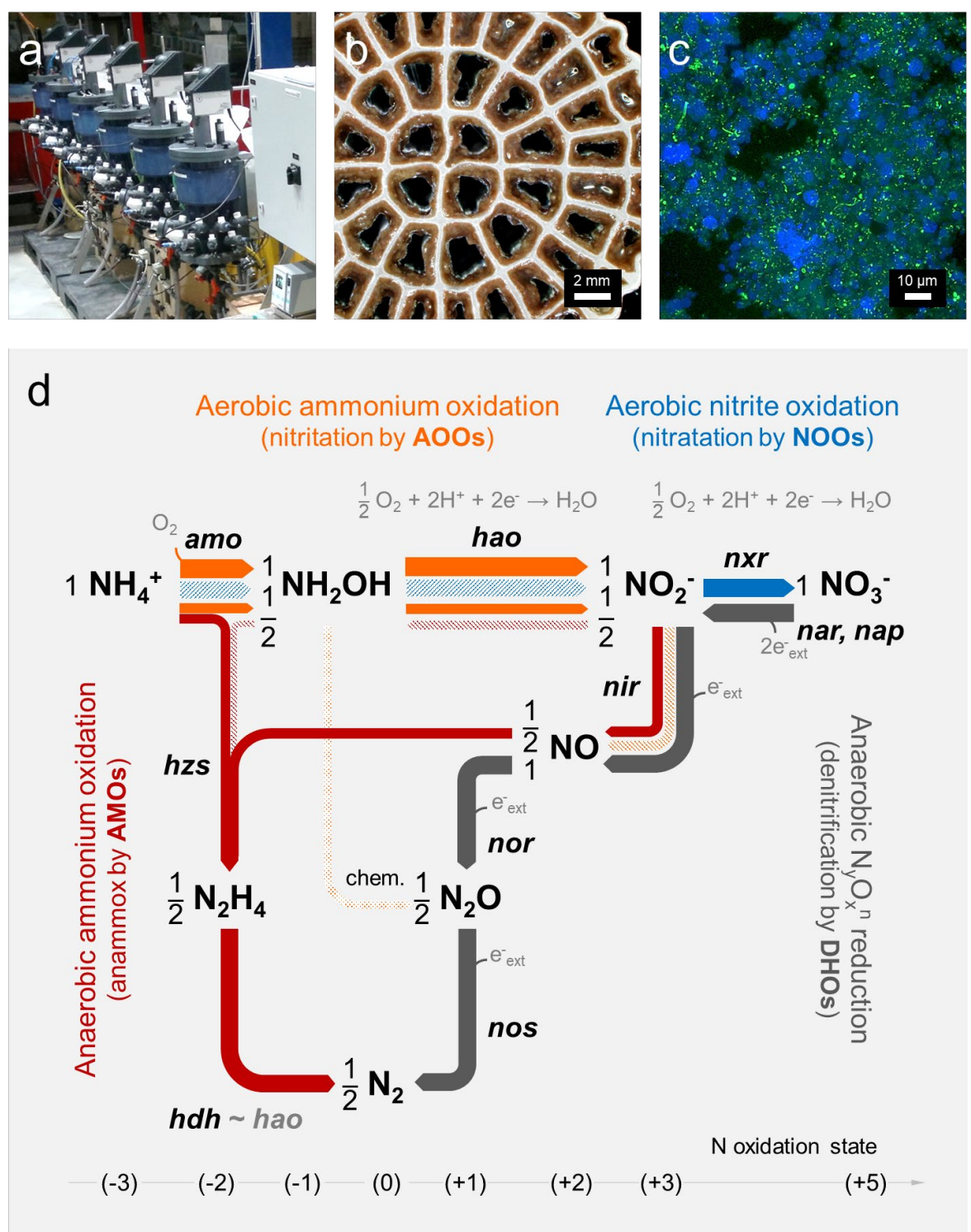

Figure 2. Multi-level investigation approach in the engineering context of partial nitritation and anammox (PN/A). The macro scale (a): replication at process level is desirable since providing substantial power in data analysis. The meso scale (b): PN/A can notably be efficiently implemented in attached-growth mode such as exemplified by this biofilm carrier. The micro scale (c): inside biofilms and bioaggregates microorganisms occupy different niches by forming microcolonies (here clusters of auto-fluorescent anammox cells; blue color allocation) inside a matrix of extracellular polymeric substances (here matrices of glycoconjugates stained using fluorescent lectins; green color allocation). The molecular and metabolic scales (d): systems microbiology investigations should start with a simplified sketch of typical network of microbial guild and metabolic pathways of experienced in engineering practice. Here the simplified catabolic network of the nitrogen cycle inside PN/A systems: the engineered combination targets partial aerobic oxidation of ammonium $\left(\mathrm{NH}_{4}{ }^{+}\right)$into hydroxylamine $\left(\mathrm{NH}_{2} \mathrm{OH}\right)$ and nitrite $\left(\mathrm{NO}_{2}{ }^{-}\right)$( $\left(\mathrm{sO}^{-\mathrm{called}}\right.$ nitritation; orange) and anaerobic oxidation of the ammonium residual by nitrite via nitric oxide (NO) into hydrazine $\left(\mathrm{N}_{2} \mathrm{H}_{4}\right)$ and dinitrogen $\left(\mathrm{N}_{2}\right.$ ) (so-called anammox; yellow) both under autotrophic conditions (i.e., carbon source from $\mathrm{CO}_{2}$ ), while pathways of nitrite oxidation into nitrate $\left(\mathrm{NO}_{3}{ }^{-}\right.$) (so-called nitratation; green) and heterotrophic (i.e., using organic carbon) reduction of nitrate and nitrite into dinitrogen via nitric and nitrous oxide $\left(\mathrm{N}_{2} \mathrm{O}\right)$ should be prevented (so-called denitrification; white). 


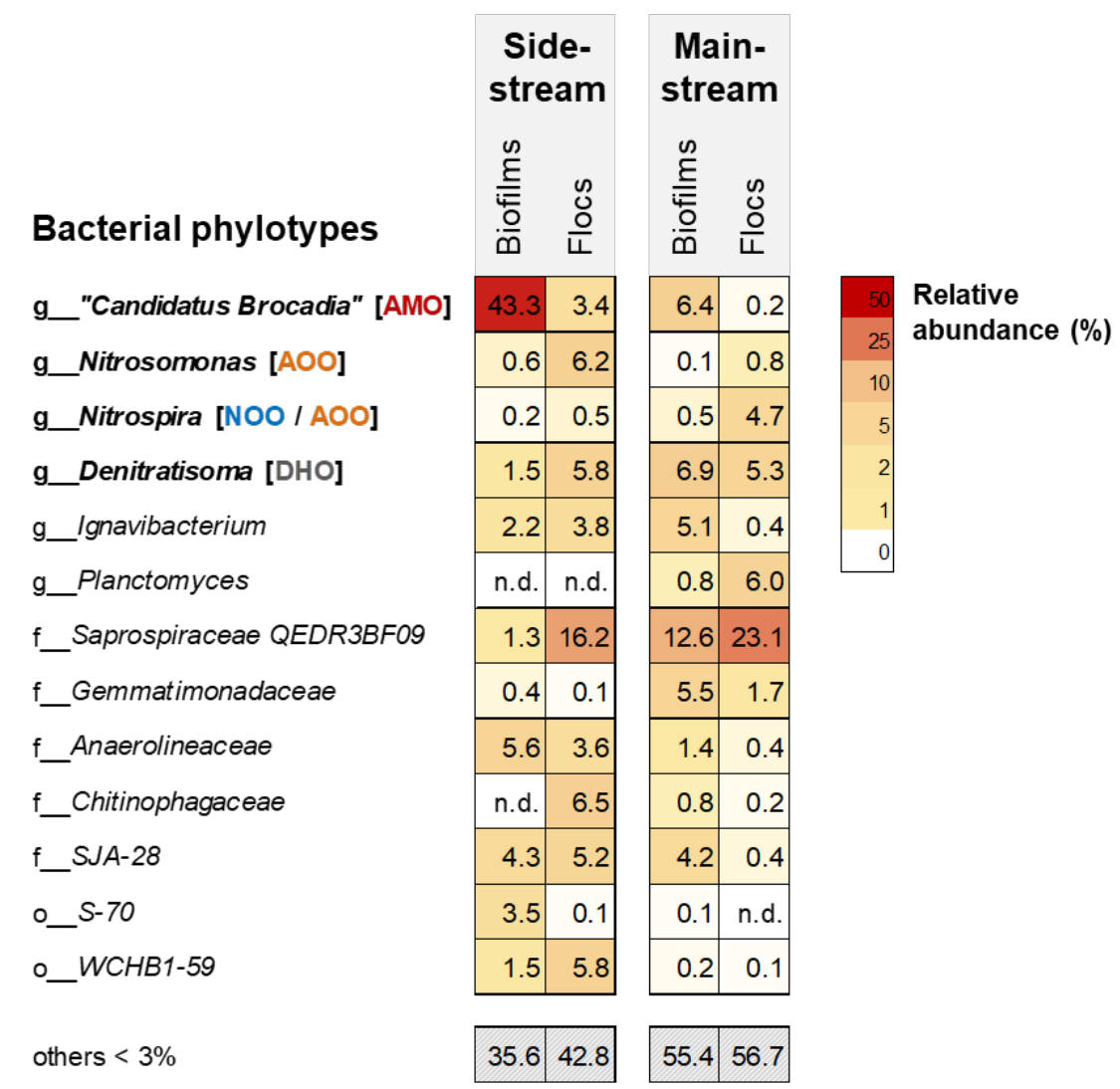

Figure 3. Comparison of bacterial community compositions of bioaggregates sampled from sidestream and mainstream PN/A processes operated at the Eawag experimental hall (Dübendorf, Switzerland) as sequencing batch reactors with high $\mathrm{N}$-loaded anaerobic digester supernatant and with low N-loaded pre-treated municipal wastewater (i.e. organic matter removed beforehand), respectively. In both sidestream and mainstream systems, the AMO genus "Ca. Brocadia" was mainly detected in the biofilms, whereas the AOO genus Nitrosomonas displayed higher relative abundances in the flocs. The NOO genus Nitrospira was mainly detected in flocs at mainstream. The DHO genus Denitratisoma was present in both types of aggregates at sidestream and mainstream. A diversity of heterotrophic organisms and candidate taxa was accompanying the traditional PN/A populations. Saprospiraceae affiliates were abundant, notably in the flocs, and are known to hydrolyse complex carbonaceous substrates. In term of diversity, ca. 30 and 110 operational taxonomic units (OTUs) formed the 75\% of the 16S rRNA gene-based amplicon sequencing datasets generated with adaptation to the MiDAS field guide ${ }^{94}$ targeting the $\mathrm{v} 4$ hypervariable region (Table 1 : primer pair 515F / 806R). Taxonomic cutoffs: $\operatorname{kingdom}(\mathrm{k})>\operatorname{phylum}(\mathrm{p})>\operatorname{class}(\mathrm{c})>\operatorname{order}(\mathrm{o})>$ family $(\mathrm{f})>$ genus $(\mathrm{g})>\operatorname{species}(\mathrm{s})$.

At metabolic scale, nitrogen conversions should be controlled across the microbial catabolic network along gradients of electron donors and acceptors. Engineering measures should balance flows of dissolved oxygen and nitrogen from ammonium $\left(\mathrm{NH}_{4}{ }^{+}\right)$to dinitrogen $\left(\mathrm{N}_{2}\right)$ via central intermediates of nitrite $\left(\mathrm{NO}_{2}^{-}\right)$and nitric oxide (NO), and prevent the unfavorable emission of nitric (NO) and nitrous oxides $\left(\mathrm{N}_{2} \mathrm{O}\right)$ greenhouse gases along PN/A 95-102. Operational control should embrace a detailed experimental and mathematical understanding of physical-chemical and physiological phenomena 100,103-105. In contrast to their aerobic counterparts 106,107 , AMOs have not yet been isolated and cultivated in pure cultures. Tackling their ecophysiology is challenging. To date, the anammox microbiology has been thoroughly investigated in high- grade enrichments and co-cultures ${ }^{42,108,109}$. Metabolic elucidations in combined PN/A processes can be performed via in situ and ex situ measurements $29,110,111$.

At molecular scale, critical open questions cover multiple levels beyond the microbial and functional ecology of PN/A systems to unravel cellular mechanisms of metabolic regulation (Fig. 4). On the ecological perspective, molecular biology analyses target microbial community compositions ${ }^{29,32,112-}$ 114, guild and population differentiation and stratification inside bioaggregates ${ }^{59,89,115-117}$, population selection, dynamics and regime shifts ${ }^{118,119}$, and functional genetic potential ${ }^{120}$ and expressed metabolisms ${ }^{109}$. 

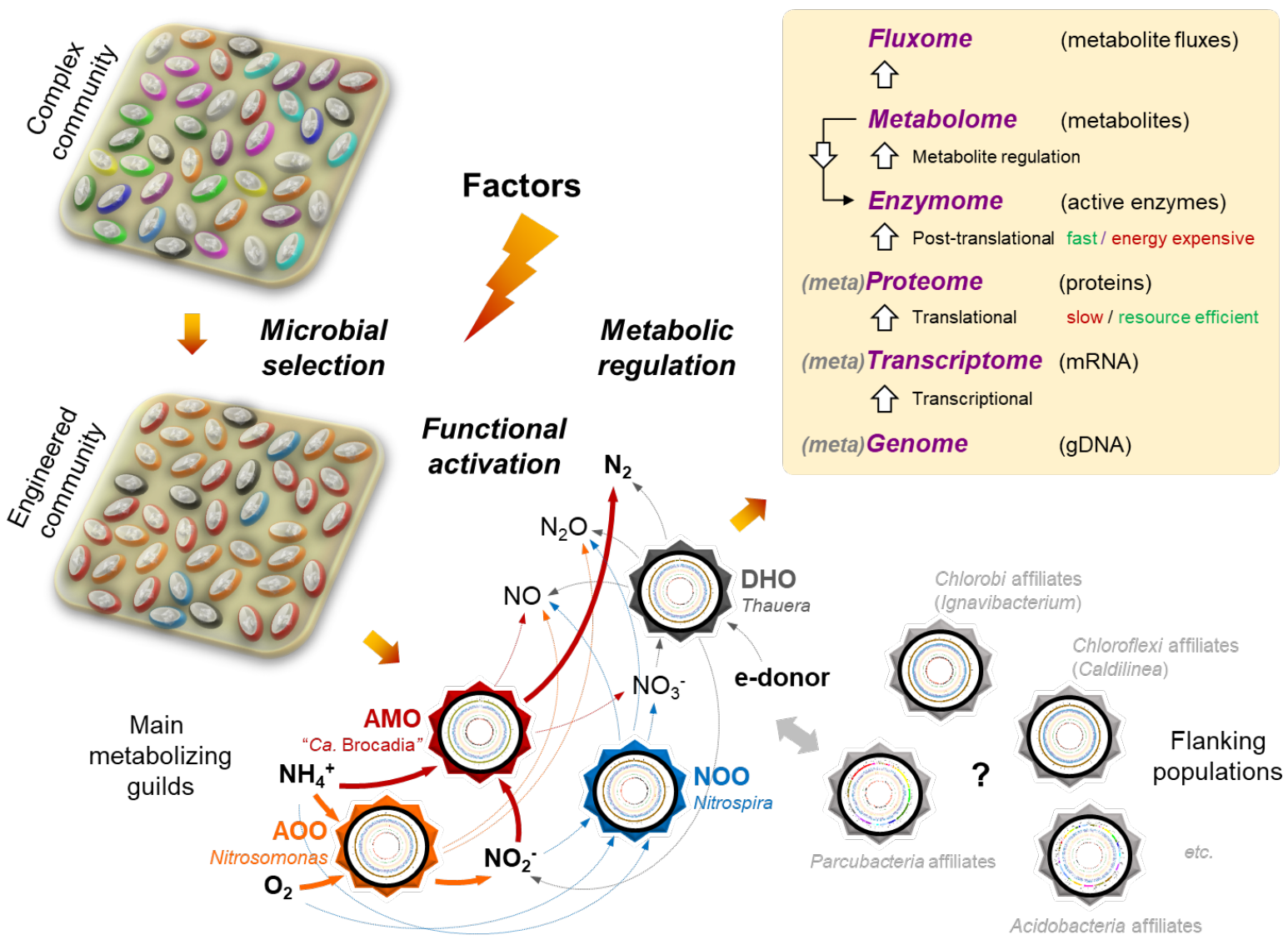

Figure 4. Molecular investigations of PN/A processes involve the examination of community compositions, microbial selection, functional activation, and metabolic regulation phenomena in the vicinity of the ecosystem. Community systems microbiology targets the microbial and functional ecology of the mixed-culture biosystem toward the formulation of conceptual ecosystem models ${ }^{49}$. The impacts of environmental and operational conditions are studied possibly using multifactorial experimental designs ${ }^{121}$ are studied on the selection of bacterial populations of functional interest e.g. within the AOO, AMO, NOO and DHO guilds. Systems biology approaches subsequently aim for the use of single-lineage genomes that can be recovered from the metagenome sequenced from the community genome schemes taken from ${ }^{43}$ in order to subsequently study the metabolic regulation behaviors of these specific populations under operational variations: this involve complex multi-level processes triggered from gene transcription to mRNA, its translation to proteins, post-translational processes for enzymes activation, and metabolite flux regulation ${ }^{122}$. The analysis of single regulation processes (e.g. transcriptional pattern or translational pattern only) is not solely sufficient to unravel the metabolic states of the organisms. Measuring metabolic fluxes on top of genomic information provides excellent insights, prior to examining the challenging intermediate transcriptional, translational, and posttranslational patterns. Consistent experimental and sampling designs are required since regulation processes perform at different rates and may occur independently.

Examination of metabolic regulation in microorganisms and communities is challenging since this involves a multitude of transcriptional (i.e., mRNA level), translational (proteins), post-translational (enzyme activation), and metabolite-flux-based regulatory mechanisms ${ }^{122-130}$. Regulatory controls underlying the biochemical performance of PN/A are mostly unexplored. Transcriptional patterns using gene expression assays or metatranscriptomics provide a proxy for functional activation ${ }^{131-136}$. Thorough insights in the metabolism of populations of interests at the microbiome level will require a combination of molecular approaches along regulation processes. Measurements of fluxes of selected metabolites ${ }^{109}$ should validate the functional potential displayed by their single-lineage genomes recovered from metagenomes ${ }^{43}$ of PN/A communities.

\subsection{Good practices to engineer PN/A microbial com- munities}

In contrast to axenic biological systems operating with one single organism, good practices of microbial resource management (MRM) ${ }^{137,138}$ and microbial community engineering (MCE) ${ }^{139,140}$ are 
needed to handle mixed cultures as complex as activated sludge ${ }^{141}$. While the two terminologies stand for the same outcome, MCE provides the dimension of engineering the conditions to achieve MRM. MCE is essentially a deterministic approach that largely relies on either empirical stoichiometric, kinetic, and thermodynamic characterizations from bulk measures of total and active biomass. The abundance of coarsely defined popula- tions is at most considered. Probabilistic phenomena need to get considered as well ${ }^{142}$. MRM and MCE strategies helped to manage, engineer and control the performance of the microbial communities of one-stage anammox-based processes ${ }^{79,143}$. A further illustration of MRM in PN/A is discussed in Text box 2 based on research efforts that have been made to prevent the proliferation of NOOs in PN/A systems.

\section{Text box 2}

\section{Preventing proliferation of NOOs: a leading illustration of bacterial resource management}

Considerable efforts have been undertaken from bench to pilot to full scale to optimize PN/A under the scope of suppressing NOOs. Conditions have been widely tested to suppress NOOs such as displayed by the diversity of studies reported in literature on this particular research question $23,29,32,38,60,65,81,96,144-158$.

Among the different reports available in literature and cited above, most proposed strategies aim at limiting the energetic catabolic activity of NOOs. A recipe aggregating different parameters of these different alternatives has interestingly been formulated for plug-flow mainstream systems ${ }^{153,154,159}$. Models have been formulated and used to delineate optimal operational win-

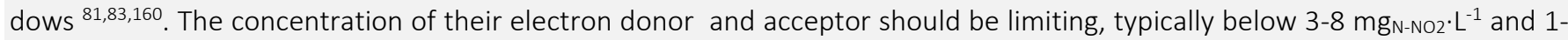
$1.5 \mathrm{mg}_{02} \cdot \mathrm{L}^{-1}$, respectively. These endpoints request the mastering of the oxygenation of the bulk liquid phase, either by using a control loop on dissolved oxygen or by stoichiometric control to meet with the minimum aeration rate required for a partial aerobic oxidation of the ammonium load. Transient anoxia via intermittent aeration by rapidly transitioning from aerobic to anoxic conditions has been reported to possibly de-activate and efficiently out-select NOOs, but may lead to substantial $\mathrm{N}_{2} \mathrm{O}$ emission. Besides, these studies also point out that high bicarbonate $\left(1200-2350 \mathrm{mg}_{\mathrm{HCO}} \cdot \mathrm{L}^{-1}\right)$ and residual ammonium concentrations of 10-40 and 2-4 $\mathrm{mg}_{\mathrm{N}-\mathrm{NH} 4} \cdot \mathrm{L}^{-1}$ have also been beneficial for the efficiency of sidestream and mainstream systems, respectively. The ratio between ammonium and dissolved oxygen in the bulk ${ }^{81}$ has notably been shown to be manageable for maximizing AOB growth relative to NOB. So-called "aggressive" control on aerobic sludge retention times ${ }^{159}$ are applied based on affinity constants and maximum specific growth rates of $A O B$ and NOB. Low temperature which occurs on seasonal variations encountered in municipal WWTPS can further result in lower nitrogen removal rates and in the proliferation of NOOs, so that mesophilic conditions are expected to sustain PN/A. Overall, strategies can either target inhibition and/or non-ideal conditions for NOB or beneficial conditions for NOB competitors, or ideally both.

Various effects have been studied by step-wise elucidation and control of operational conditions at process scale, and act as strong basis for the development of wider strategies for implementing microbial resource management (MRM) into PN/A systems ${ }^{79}$. A good practice of MRM should definitely go via consideration of the ecophysiological and metabolic traits within the microbial guilds and underlying populations involved in the process, as an opportunity to improve bioprocess designs and control. Suppressing NOOs from the system is one aspect, but strategies should target microbial community engineering as a whole over the microbiome of PN/A systems.

To be useful, MRM and MCE should account for ecological principles of microbial selection that are primarily linked to fundamentals of enrichment cultures developed in the early 1900's by Beijerinck and revisited by De Wit and Bouvier ${ }^{161}$. Predicting microbial community function and dynamics is a grand challenge of microbial ecology 162. Deterministic and stochastic factors shape the microbial compositions and functional performances of communities 121,142,163-167. Environmental and operational factors can be engineered to reach and switch between performance steady states, that also link to selection-driven community assembly. Stochastic (or probabilistic) effects govern neutral community assembly and variations, and should not be forgotten when managing microbial communities under pseudo steady-state conditions on the long run ${ }^{164}$. The latter seem less manageable in engineering, but request full attention because of the predictable propensity of stochastic developments in shaping community compositions and functioning, and therefore their impact on process performance. Theoretical ecological principles or "laws" that target questions of, e.g., diversity-stability relationships, disturbance theory, network stability and importance of neutral processes $118,142,168,169$ can provide a foundation upon which 
the more practical engineering (that always target the particular system being worked on) can be built. Modeling the risk of failure of the biological system using rather simple mathematical-statistical models can aid to integrate probabilistic patterns into the engineering rationale ${ }^{170,171}$. Reliability engineering and modelling allow for analyzing the stability, redundancy and resilience of complex networks of microbial populations, metabolic functionalities, and interactions. It leads to identifying failure-prone biochemical pathways that require closer look and surveillance. It fills the gap between ecosystem assessment, design and management in mixed-culture environmental biotechnologies like PN/A processes.

\subsection{Microbial guilds of engineering interest for PN/A}

The AMO guild comprises five known candidate genera of the phylum Planctomycetes affiliating with "Ca. Brocadia", "Ca. Kuenenia", "Ca. Anammoxoglobus", "Ca. Jettenia" and "Ca. Scalindua", enriched and characterized from fresh and saline water environments and full-scale anammox systems ${ }^{6,120,172}$. "Ca. Brocadia" populates systems fed with digester supernatants ${ }^{173,174}$, source-separated urine ${ }^{27}$, and municipal wastewater ${ }^{29,32}$. " $\mathrm{Ca}$. Kuenenia" displays higher affinity for nitrite, and dominates at low concentrations of this terminal electron acceptor ${ }^{72,113,175}$. This genus outcompetes "Ca. Brocadia" under shorter hydraulic retention time (HRT) ${ }^{176}$.

The AOO guild comprises populations ranging from ammonium-oxidizing bacteria (AOB; e.g., Nitrosomonas, Nitrosospira, Nitrosococcus, etc.) 177 to archaea (AOA; e.g., Nitrosoarchaeum, Nitrosopumilus, Nitrosocaldus, etc.) ${ }^{178}$. In PN/A systems, AOOs are uniformly dominated by the autotrophic $\beta$-proteobacterial Nitrosomonas-Nitrosospira AOB lineage that is established under neutral or slightly alkaline wastewater conditions. AOA have mainly been not examined in high ammonium-loaded PN/A processes ${ }^{179,180}$. Heterotrophic bacterial lineages of Pseudomonas, Xanthomonadaceae, Rhodococcus, and Sphingomonas can contribute to ammonium oxidation in biological systems operated at low dissolved oxygen concentration $\left(<0.3 \mathrm{mgO} \cdot \mathrm{L}^{-1}\right){ }^{181}$. This is the typical oxygenation level imposed to PN/A flocculent sludges or experienced inside the PN/A biofilms.
Populations of the undesired NOO guild mainly relate to Nitrobacter or Nitrospira depending on conditions ${ }^{115,119,158}$. Nitrobacter is abundant at higher concentration of nitrite ${ }^{145}$. Latest metabolic highlights on Nitrospira sub-lineages that can perform a complete oxidation of ammonium to nitrate ${ }^{8,182}$ may lead to reconsideration of the competitive mechanisms between AOOs and NOOs in PN/A systems. The involvement of non-canonical NOOs such as the genus Nitrolancea inside the phylum of Chloroflexi ${ }^{183}$ should also be elucidated along competitive interactions within PN/A processes.

\section{Driving bioanalytical targets using microbial and functional ecology questions}

The microbial ecology science takes advantage of a broad set of analytical methods ${ }^{184}$ that the engineering field is not yet fully acquainted with. Guidance should now be provided in a rational context of engineering. Training of process ecologists is required as novel educational and professional specialization. The diversity of methods with their set of applicability and limitations make their choice not straightforward. Method selection should be carefully driven by research questions and hypotheses formulated upfront to designs of experiments.

\subsection{Investigating microbial lineages of PN/A ecosys- tems: how far to go?}

From lineage differentiation, the next question addresses the need, or lack thereof, to understand the microbial system with higher resolution. PN/A processes and biological wastewater treatment in general are primarily engineered and controlled for microbial selection and nutrient conversions at guild level without much concern about the phylotypes involved. Microbial community analysis has nonetheless been addressed as the key to an optimized design based on critical biocatalysts (i.e., the microorganisms) rather than on black or grey-box design principles ${ }^{185}$. An integration of both concepts addressing that ecological conditions and microorganisms drive process design is needed.

It can be questioned whether phylogenetic differentiation does impact operation schemes. In other words:

- Does PN/A perform differently in the presence of one or the other bacterial and archaeal genus 
of the AOO guild and population of the AMO guild?

- Does the prevalence of either Nitrobacter or $\mathrm{Ni}$ trospira affiliated NOOs make a significant difference to engineer strategies for their suppression?

- Do accompanying populations of lower engineering interest impact the distributed efficiency of the PN/A microbiome?

Flanking populations of the guild of ordinary heterotrophic organisms (OHOs) have been essentially ignored and not characterized in detail. Their putative effect on PN/A performance have not yet been made evident in the rational engineering context. OHOs and DHOs may enter the competition for dissolved oxygen and nitrite if readily biodegradable organic matter is present in sufficient residual concentrations in the PN/A tank $75,145,186$. This can occur at sidestream if anaerobic digestion is incomplete or at mainstream when organics are not fully removed beforehand in a high-rate activated sludge process ${ }^{153,187}$. These faster-growing heterotrophic organisms may also physically structure the bioaggregates by producing extracellular polymeric substances ${ }^{87,116,188-191}$. Synergetic relationships can also underlie the proliferation of OHOs in PN/A systems ${ }^{192}$, by thriving on soluble microbial products produced in the ecosystem ${ }^{193-}$ 196.

Future investigations should also elucidate impacts from predation by bacteriophages and protists ${ }^{197-}$ ${ }^{204}$ on the performance of the PN/A community $12,85,205$

Experimental research and mathematical modelling needs to be combined to better understand interactions inside PN/A microbiomes, and environmental factors that trigger them. Fine-scale lineages may exhibit metabolic and physiological features that induce niche segregation and impacts on process behavior. This has been exemplified by modelling of microbial and aggregate heterogeneity in nitrifying biofilms after in silico seeding of 60 artificial populations of each of the AOO and NOO guilds ${ }^{86}$.
The ecosystem performance relies on the "health state" of the microbial community ${ }^{141,164,206}$. According to the low number of predominant populations present, PN/A biomass may display lower richness and diversity than activated sludge from processes designed for full biological nutrient removal (BNR). If true, this feature may indicate lower functional redundancy and lower robustness to operational and environmental variations ${ }^{164}$. While biosystem robustness can be investigated at the level of overall bacterial community composition, microbial and functional diversity at guild and lineage level should also be considered. Even a highly diverse community may involve functionally key microbial guilds, like AMOs, that are made up of only a few lineages. If out-competed, the process will never achieve the desired PN/A performance.

This is illustrated here by multivariate numerical analyses of process failure followed over three months in a sidestream sequencing batch reactor operated under suspended-growth regime for PN/A (Fig. 5a). Unfavorable high accumulation of nitrite was correlated to higher richness and diversity of the amplicon sequencing dataset (Fig. 5b). This may look at first sight counter-intuitive. However, while a highly stable equilibrium was reached under nitrite accumulation, insight on functional guilds revealed outselection of the AMO genus "Ca. Brocadia" and proliferation of the AOO genus Nitrosomonas under these conditions (Fig. 6).

An attached-growth system operating in parallel on the same anaerobic digester supernatant performed $\mathrm{PN} / \mathrm{A}$ adequately at negligible nitrite accumulation $\left(<5 \mathrm{mgN}_{\mathrm{N}} \mathrm{L}^{-1}\right)$ with a bacterial community dominated by " $\mathrm{Ca}$. Brocadia" and exhibiting higher richness and diversity than the initially well-functioning flocculent sludge system. Deterministic selection and probabilistic phenomena (such as extinction or invasion events) should be considered jointly when investigating microbial community assemblies. This is an excellent example where concepts of engineering and theoretical ecology meet. More research is needed to better bridge the two approaches. 

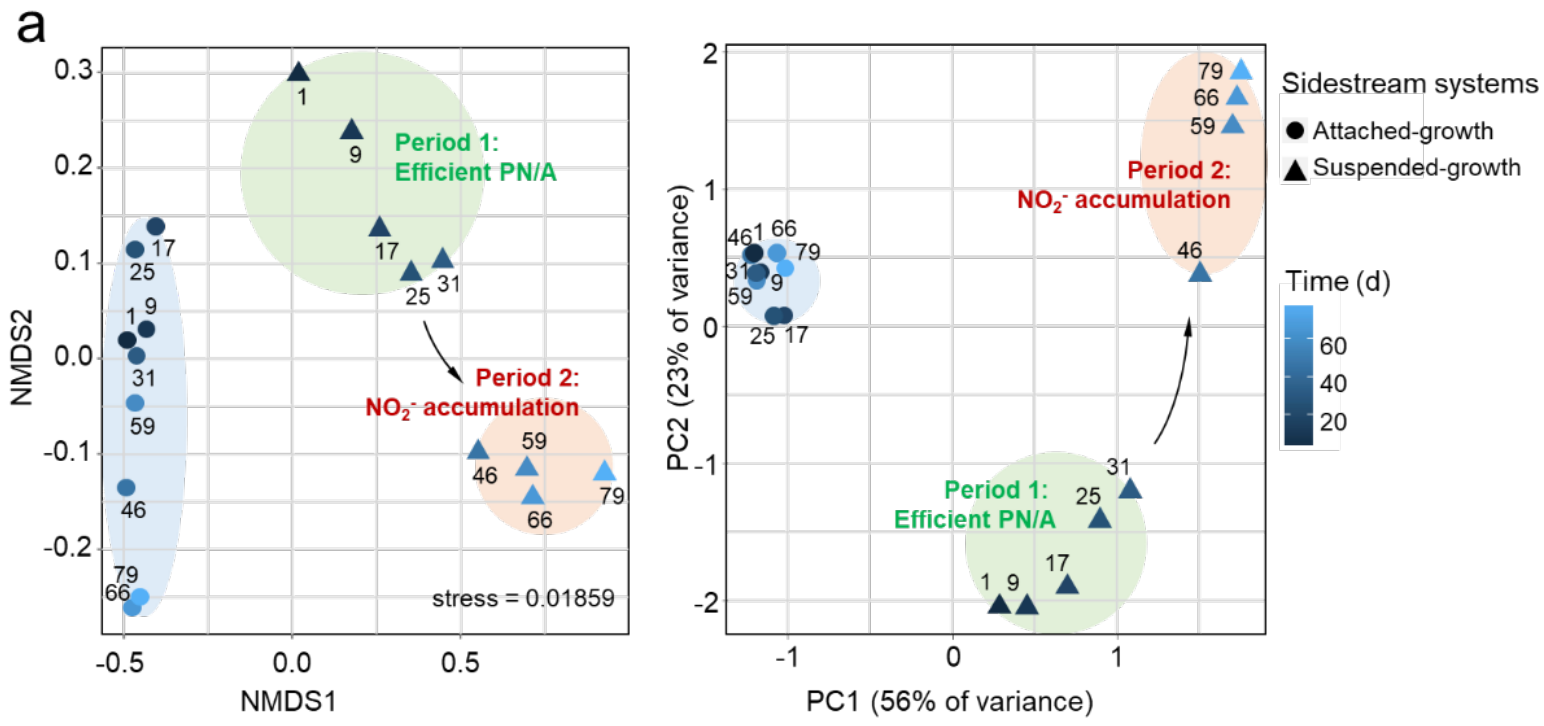

b

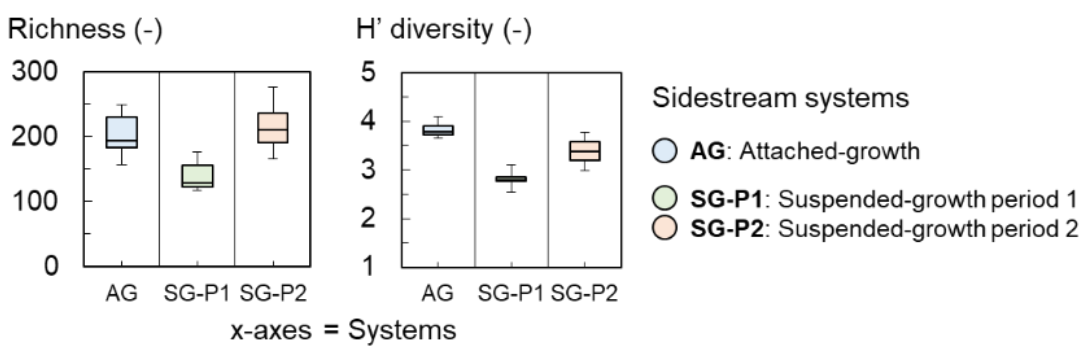

Figure 5. Multivariate numerical analysis of dynamics in bacterial community compositions in stable attached-growth (i.e., biofilm-based; circles) and failing suspended-growth (i.e., floc-based; triangles) PN/A systems operated in parallel on the same digester supernatant under sequencing-batch conditions; see Fig. 6 for community patterns measured by v4 16S rRNA gene-based amplicon sequencing analysis at a median sequencing depth of 39'000 reads and processed using the MiDAS field guide to the microbes of activated sludge ${ }^{94}$. The non-metric multidimensional scaling (NMDS) and principal component analysis (PCA) (a) jointly reveal a significant change in bacterial community composition during the transition from favorable process performance on period 1 (i.e., no nitrite accumulation $<5 \mathrm{mg}_{N} \cdot \mathrm{L}^{-1}$ ) to process failure on period 2 (i.e., unfavorable nitrite accumulation up to more than $200 \mathrm{mgN}_{\mathrm{N}} \mathrm{L}^{-1}$ ) in the floc-based PN/A process. This PN/A-wise unfavorable transition was surprisingly accompanied by an increase in the richness and Shannon $\mathrm{H}^{\prime}$ diversity indices of the amplicon sequencing datasets (b): this is actually not an apparent counter-example to theoretical ecology axioms considering system robustness proportional to microbial richness and diversity since the unfavorable process of nitrite accumulation reached a more stable equilibrium and performance than the desired PN/A process. One should consider that a desired robust engineered performance may fall into a different referential than a true robust microbial system.

3.2 Which taxonomic molecular method to choose: is this the research question?

Molecular measurements conducted during process engineering investigations are mainly limited to fingerprinting techniques targeting the $16 \mathrm{~S}$ rRNA gene or 16S-23S intergenic spacer $113,118,131,207,208$, and, increasingly, to amplicon sequencing to analyze bacterial community compositions 29,32,118,132,209. Methods of 16S rRNA targeted fluorescence in situ hybridization (FISH) are combined with epifluorescence or laser-scanning microscopy to detect, localize and quantify the relative abundances of guilds or populations of interest 59,115 .
Quantitative real-time polymerase chain reaction (qPCR) has been applied to some extent to provide quantitative information of population shifts and of expression levels of functional genetic biomarkers $112,131,132,134,210$.

The problem of deciding on the most adequate molecular method to select arises in most of scientific discussions. Again, the selection should first rely on clearly formulated research questions prior to screening for analytical technologies to implement. Molecular biology research should rely on designs as consistent as and made in parallel to experimental designs aimed at process level. 
Community fingerprinting and amplicon sequencing provide similar information on microbial community structures (bacterial, archaeal, eukaryal depending on primers used), with the advantage of amplicon sequencing to directly provide affiliations to sequences forming operational taxonomic units (OTUs) or also increasingly referred to unique amplicon sequence variants (ASVs) ${ }^{211}$. Dynamics of bacterial community compositions can be followed with high phylogenetic and temporal resolutions and can be efficiently correlated to reactor regimes using numerical ecology $50,87,118,212$ and linked by means of multifactorial experimental designs to identify the factors influencing population selection and community assembly ${ }^{121}$. In hybrid systems operated for PN/A by involving both attached-growth and suspended-growth regimes, the differences in microbial community compositions of flocs and biofilms can be studied by sampling the two fractions adequately ${ }^{59,115}$.

The method to extract and purify genomic DNA (gDNA), the quality of the purified gDNA template (which varies with the method of isolation), the choice of universal primers and hypervariable regions targeting 16S (bacteria, archaea) and 18S (eukarya) rRNA gene pools, PCR conditions, sequencing workflow, and quality of the on-line database used to map sequencing reads can significantly impact the final measured community patterns ${ }^{213-221}$.

The full power of amplicon sequencing datasets has frequently not been harnessed in contemporary studies. These data are often simplified back to sole identification of phylotypes of traditional guilds of interest, while long term microbial developments in terms of, e.g., community structure, diversity, and co-occurrence networks are rarely considered. Nonetheless this approach forms an excellent basis toward the establishment of applied systems microbiology in the engineering context ${ }^{50,222,223}$.

FISH and qPCR are used to target guilds and lineages of interest and to follow them over different spatial and time scales, while providing quantitative information ${ }^{224,225}$. FISH offers the advantage of visualizing cells and cell assemblages under the microscope, yielding a dimension of spatial information that cannot be obtained with other methods. FISH is also considered to provide information on the state of activity of target organisms (related to ribosome content), but this assumption is not valid for AMOs ${ }^{226}$. FISH is applicable mostly to abundant targets, in typical implementations cells with an abundance below $1 \%$ are difficult to quantify. qPCR offers a much lower detection limit. qPCR is also not limited to ribosomal targets, allowing to target guilds based on functional gene targets. Such functional gene analysis can nicely be complemented using the RING-FISH method combining FISH to recognition of individual genes (RING) in single cells ${ }^{227,228}$.

All hybridization methods have their degrees of confidence and mismatch. They rely on the design and specific binding of oligonucleotides to the genomic DNA (gDNA) or ribosomal RNA (rRNA) of microorganisms to be analyzed using PCR-based (e.g. fingerprinting, amplicon sequencing, $\mathrm{qPCR}$ ) or FISH methods, respectively. Difficulties may arise both at the design stage (e.g., identification of primer sites of suitable specificity to discriminate against all or most non target sequences and generality toward inclusions of all or most target sequences) and during laboratory implementation. Field guides ${ }^{94,224,229}$ have been proposed to investigate activated sludge biocoenoses. Guidelines should be adequately adapted to the function of the studied biosystem, biomass properties, targeted microorganisms, and molecular objectives. Quality assurance by preliminary testing of biomass matrices, integration of reference samples of known compositions, and combination of different methods (e.g., amplicon sequencing and qFISH or qPCR) to cross-validate results and offset individual weaknesses of methods is essential for robust analyses of microbial communities.

Table 1 shows the power of in silico analyses in the design of molecular methods for the preliminary testing and selection of oligonucleotide PCR primers and FISH probes adequate for analytical targets. In silico testing is recommended 221,230,231. This needs to be carefully included in the evaluation of the toolset for new research project involving microbial community analyses, taking the specific requirements arising from the research question and studied system into account (Text box 3). Optimization of PCR and FISH conditions and validation at wet-lab using representative biological samples are required. 
Table 1. Targeting the "universal": in silico analysis of the impact of the choice of the pair of PCR primers along the hypervariable regions of the 16S rRNA gene on the bacterial diversity covered in PN/A systems against the Silva database of above 400,000 reference sequences of $16 \mathrm{~S}$ rRNA genes ${ }^{232}$ following the procedure of Klindworth, et al. ${ }^{231}$ with one mismatch allowed in the primer sequence. Universal primer pairs were considered, as well as specific and semi-specific ones to the guild of anammox organisms (AMOs) designed by combining an anammox-specific forward primer with a universal reverse primer.

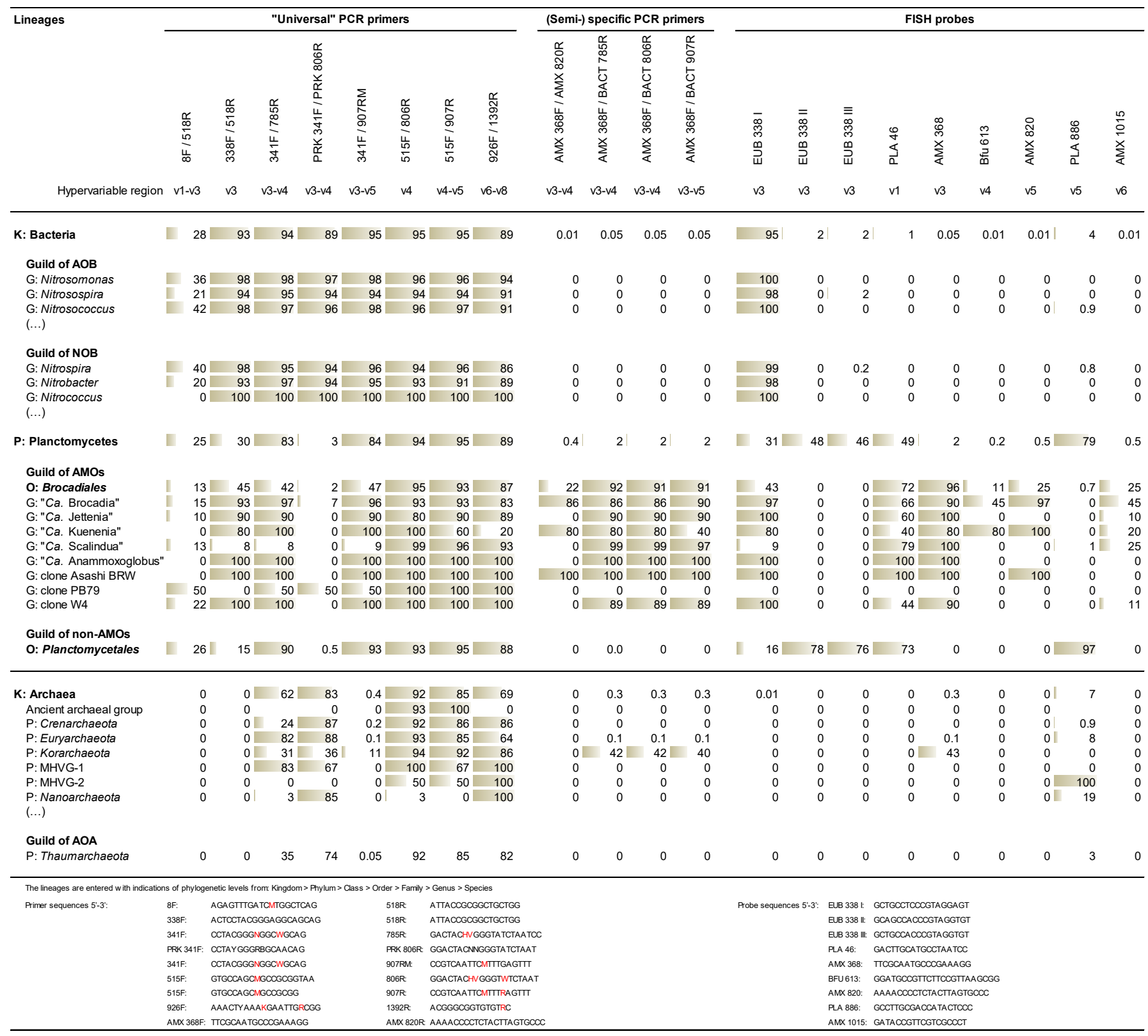


Text box 3

\section{In silico testing of oligonucleotides: a prerequisite to cover AMOs with the broader bacterial community}

One efficient way to integrate molecular methods in practice is to start with amplicon sequencing analysis of selected biological samples to screen populations composing the bacterial community of interest. Different sets of primer pairs should preliminarily be tested in silico along the hypervariable regions of the 16S rRNA gene pool and PCR conditions optimized at wet lab. FISH probes or qPCR primers can then be selected or designed starting from the sequencing datasets in order to target specific phylotypes along operation.

Dry-lab analyses of oligonucleotide PCR primers and FISH probes were conducted here against the Silva database of $16 \mathrm{~S}$ rRNA gene-based reference sequences ${ }^{232}$ following Klindworth, et al. ${ }^{231}$, and highlighted that some key populations of the PN/A ecosystem may indeed not be detected depending on the hypervariable region targeted (Table 1 ) and due to primer biases. This analysis highlighted that a pair of universal eubacterial primers such as the BACT 515F / BACT 806R targeting the v4 hypervariable region of the 16S rRNA gene should preferentially be selected for detecting anammox populations while covering the broader bacterial community composition in amplicon sequencing datasets, matching with earlier wet-lab reports ${ }^{32}$ and that we previously reported in Laureni, et al. ${ }^{29}$. On top of covering the bacterial guilds of $\mathrm{AOO}$ s and AMOs, this primer pair targeting the v4 region is also interesting for simultaneous detection of ammonium-oxidizing archaea (AOA) with theoretical coverage of $96 \%$ of references sequences of the Silva database.

As an important notice, the traditional primer pairs targeting the v1-v3 region (e.g., BACT 28F / BACT 518R) such as recommended in the MiDAS field guide of activated sludge ${ }^{94}$ are not suitable to these key analytical ends in the investigation of PN/A systems. Dry-lab and wet-lab analyses showed that they do not allow for catching anammox lineages, besides leading to a rather low theoretical coverage of all 400'000 references sequences reported in Silva for the kingdom of bacteria.

Semi-specific pairs involving a forward primer specific to the AMO guild (namely AMX 368F) and a universal eubacterial reverse primer (e.g., BACT 785R, 806R or 907R) are further proposed in Table 1 for a specific theoretical detection of the diversity of known anammox lineages within the order Brocadiales using one single PCR run. The combination of the two specific primers AMX 368F and AMX 802R only leads to a poor coverage of anammox populations, the latter reverse primer being too specific for the "Ca. Brocadia" and "Ca. Kuenenia" genera. The theoretical coverage of the traditional oligonucleotide FISH probes used to detect AMOs are further displayed by Table 1, showing that the probe AMX 368 is the best currently available FISH probe for a theoretical coverage of $96 \%$ of the referenced Brocadiales affiliates.

Molecular analyses on the $16 \mathrm{~S}$ rRNA gene have over the last decade been described as laborious by requiring an indirect twostep PCR to amplify genetic fragments from anammox lineages inside the phylum Planctomycetes ${ }^{226}$. The in silico analysis conducted here is powerful in the sense that primer pairs over the $\mathbf{4} 4$ hypervariable region were delineated for a direct PCR followed by amplicon sequencing analysis to obtain the relative abundance of a diversity of (known) anammox populations together with the broader composition of the bacterial community in one single run.

3.3 Going for ecophysiologies and metabolic functionalities in PN/A microbiomes

Integrating molecular results with process performance ${ }^{50,212}$ and in situ or ex situ activity tests such as done for PN/A ${ }^{29,59,110}$ is interesting to associate putative drivers of community assembly among environmental variables or process control settings on the one hand and measures of metabolism, activity or process performance on the other hand to phylotypes. These associations are, however, correlation-based, and therefore remain descriptive only. Additional effort is needed to obtain mechanistic insights into the metabolisms performed in the vicinity of microbial communities or to establish causal links to environmental forcings.
Much can be learned from studies of pure cultures and much is to be gained from studying microbial metabolisms in the "wilderness" 233 of the microbial ecosystem using dedicated analytical approaches. Such as mentioned earlier, the microbial ecology science has strongly evolved together with wet-lab and dry-lab analytical breakthroughs. This allowed to progressively transition from a blackbox understanding of microbial systems to systems microbiology ${ }^{49}$, and further possibly to predictive white-box modelling.

As a proxy for microbial activity, the analysis of functional gene transcription into messenger RNA (mRNA) using reverse transcription (RT) and qPCR provides information on the current investment of the microbial community into the synthesis 
of certain enzymatic systems. This method has been applied with success to PN/A systems ${ }^{89,134}$.

Ecophysiology measurements based on additions of isotope-labeled substrates provide ultimate clues on investigated metabolic functions of microorganisms ${ }^{234}$. The combined use of FISH and microautoradiography (MAR) allows for phylogenetic identification combined with determination of uptake of a radioactively labeled substrate on the single cell level ${ }^{235-237}$. MAR-FISH has been recently used to examine whether AMOs could store radiolabeled organics and thus possibly compete with DHOs under carbon-rich environments, while mostly non-anammox side populations have been detected to conduct this metabolism under the incubation conditions used ${ }^{29}$. Other studies however have indicated that some anammox candidate genera may be capable of organotrophic growth ${ }^{143,238}$. Additional techniques like bioorthogonal non-canonical amino acid tagging (BONCAT) coupled to FISH provide excellent possibilities for an in situ detection of physiological switches inside microbial communities and environmental samples by fluorescent tracking of protein synthesis in individual microorganisms 239,240 . Ecophysiology examinations are needed to elucidate these interesting metabolic properties. The next question would examine whether such metabolism is significant or may be harnessed at process scale.

DNA-, RNA-, protein-, and phospholipids-fattyacid-based stable isotope probing (SIP), stable isotope fractionation and nanoscale secondary ion mass spectrometry (NanoSIMS) provide additional degrees of resolution to discriminate in situ and image, respectively, the metabolic transformations conducted by community members ${ }^{241-247}$. These methods rely on incubations with substrates enriched in stable isotopes of, e.g., ${ }^{2} \mathrm{H},{ }^{13} \mathrm{C},{ }^{15} \mathrm{~N}$, or ${ }^{32} \mathrm{P}$ that ends up in intracellular informational molecules (i.e., DNA, RNA, proteins) of the active organisms. NanoSIMS has been used recently to reveal that some anammox populations can incorporate organics ${ }^{248}$. As shown, molecular and ecophysiology methods can effectively be applied for an enhanced understanding of metabolic capabilities of the diverse populations in PN/A microbiomes. Substrate labelling methods nonetheless remain costly and applicable to enrichments with small sample volumes incubated under well-defined in vitro conditions. NanoSIMS provides high degree of sensitivity and resolution on the different metabolic states of the different cells present in the specimen, while restricted to a narrow field of analysis of some micrometers thus requiring measurement of numerous fields of view for statistical robustness ${ }^{246}$. The next challenge will resides in translating high-resolution analytical results on the differentiated metabolisms of single cells across the sludge.

\subsection{Unravelling PN/A microbiome functioning using high-throughput molecular approaches}

The newly established sequencing technologies provide information on signature molecules from community members at high throughput $47,120,128,133,249$. Meta- (indicates a community) genomics, transcriptomics and proteomics allow for high-resolution investigation of genetic potential (gDNA), gene transcription (mRNA) and physiological state (proteins), respectively, at the community level.

Analyses at mRNA or protein levels can be considered as a proxy for activity. From the biochemical point of view one has to consider that activity has not been factually proven until the activity of the enzyme has been verified in enzymatic assays. On the other hand however, results of in vitro enzymatic tests are not truly representative of the physiological state of the organism under the environmental conditions governing the reactor broth ${ }^{41}$. Therefore, while the groundwork on the basic biochemical functions needs to be laid first, studies on the transcriptome or proteome subsequently provide very powerful tools to elucidate activity and metabolic regulation in complex communities under in-situ conditions.

Investigating meta-omes relates to the consideration of the microbial community as one "super-organism". This has strong synergies with the classical community ecology conflict between the community as a superorganism or as an assemblage of individual species. In systems microbiology, one should aim to go beyond the "meta-" concept of the community level. The genetic and metabolic signatures of single lineages are targeted and linked in the community network. Obtaining single-lineage genomic information out of metagenomes is of paramount importance, using bioinformatics and bio- 
statistics workflows 43,129,250,251. Tentative metabolic models are constructed on a genomic basis, prior to wet-lab validation of key metabolic features with isolates or highly enriched communities, such as has been done to elucidate novel metabolic pathways (e.g., catabolic versatility, full nitrification pathway) of ammonium-oxidizing sub-lineages of the genus Nitrospira ${ }^{182,252,253}$. Metabolomics and fluxomics can efficiently overarch functional analyses to map and track metabolic dynamics and fluxes under transient regimes in the mixedculture biosystem 254,255. Nonetheless, relating fluxes to specific microorganisms in microbial communities is hardly possible, and new developments are needed to this end ${ }^{52}$. Fluxomics is mainly applicable to pure cultures (if the organism can be isolated; but less than $0.1 \%$ and $25 \%$ of organisms can be isolated from surface water and activated sludge environments, respectively) or enrichment cultures, where it is assumed that the dominant population is conducting the examined metabolic conversion.

In the wastewater field, omics have been applied to investigate dynamic BNR biosystems ${ }^{256-263}$, and are on their way to establish on the field of PN/A $120,264,265$. Genomic features of anammox lineages have been retrieved from enrichment cultures, natural environments, and engineered settings ${ }^{266-269}$.

The combination of modern and classical bioanalytical and numerical methods can support a rational investigation of microbial communities in engineered environments ${ }^{50,212,220,270,271}$. A compromise can be reached between a high-resolution and rapid analysis of microbial responses, to provide meaningful information for process design and optimization.

\subsection{A manifesto for systems-level investigations in} PN/A biotechnological research

Only few studies have addressed multi-level interactions across the biological complexity of PN/A systems ${ }^{134,272}$. Systems-level approaches are powerful to solve the biological complexity of mixedculture processes $41,50,51,87,181,212$. Investigations can start from conceptual ecosystem models 49,50,222,223,273 as illustrated here for PN/A (Fig. 6). A deep fundamental understanding of biosystem responses across all scales in association with the relevant controlling factors is a necessary foundation to strengthen strategies of microbial resource management. The latest advances in single-lineage genome-based microbial ecology can provide high resolution information on PN/A microbiomes 120,264 . Metabolic models from phylotype to microbiome level can be built from the identified phylogenetic and genotypic signatures ${ }^{91}$. Functional validation becomes essential using ecophysiology, sequencing, and mass spectrometry methods. This requires the formulation of well-defined research questions and experimental plans.

More studies on the phylogenetic and metabolic complexity of engineered microbial communities are needed to develop a deeper understanding of PN/A and translate systems microbiology findings into biotechnological concepts. The advent of microbial ecology along with continuous analytical breakthroughs in molecular biology and ecophysiology methods has led to remarkable possibilities to investigate microbial communities in wastewater treatment systems with high resolution 184,274 . The power these methods give for tracing the phylogenetic and metabolic signatures of PN/A microbial systems should be harnessed to understand how the community ecology and metabolic networks underpin functional performance, with consideration that the engineering goal is to design an ecosystem service ${ }^{275-277}$.

Implementation of microbial ecology principles at process level remains a challenge from an engineer's perspective. The ambition to manage microbial community compositions, to consider impacts of both predominant and less-abundant flanking populations, and to anticipate the performance of the distributed metabolic network for controllable and quantitative PN/A performance outputs ${ }^{162,278}$ elevates the problem to a much higher degree of complexity. Substantial fundamental and technological advances are required, before it becomes manageable. Basic science is active to find ways to handle such complexity with the advent of highthroughput wet-lab and dry-lab approaches ${ }^{262}$. The complex networks of populations and metabolisms of PN/A systems can be deciphered and a systems biology framework established at community level. 
PROCESS ENGINEERING
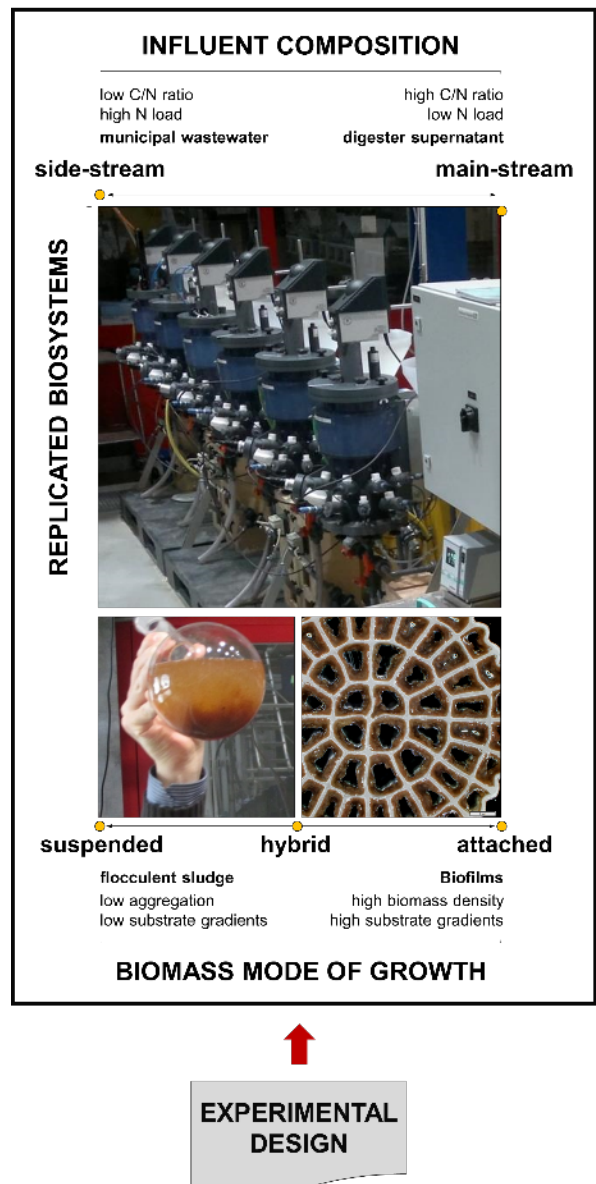

SELECTION AND ACTIVATION FACTORS

SYSTEMS MICROBIOLOGY / ECOGENOMICS

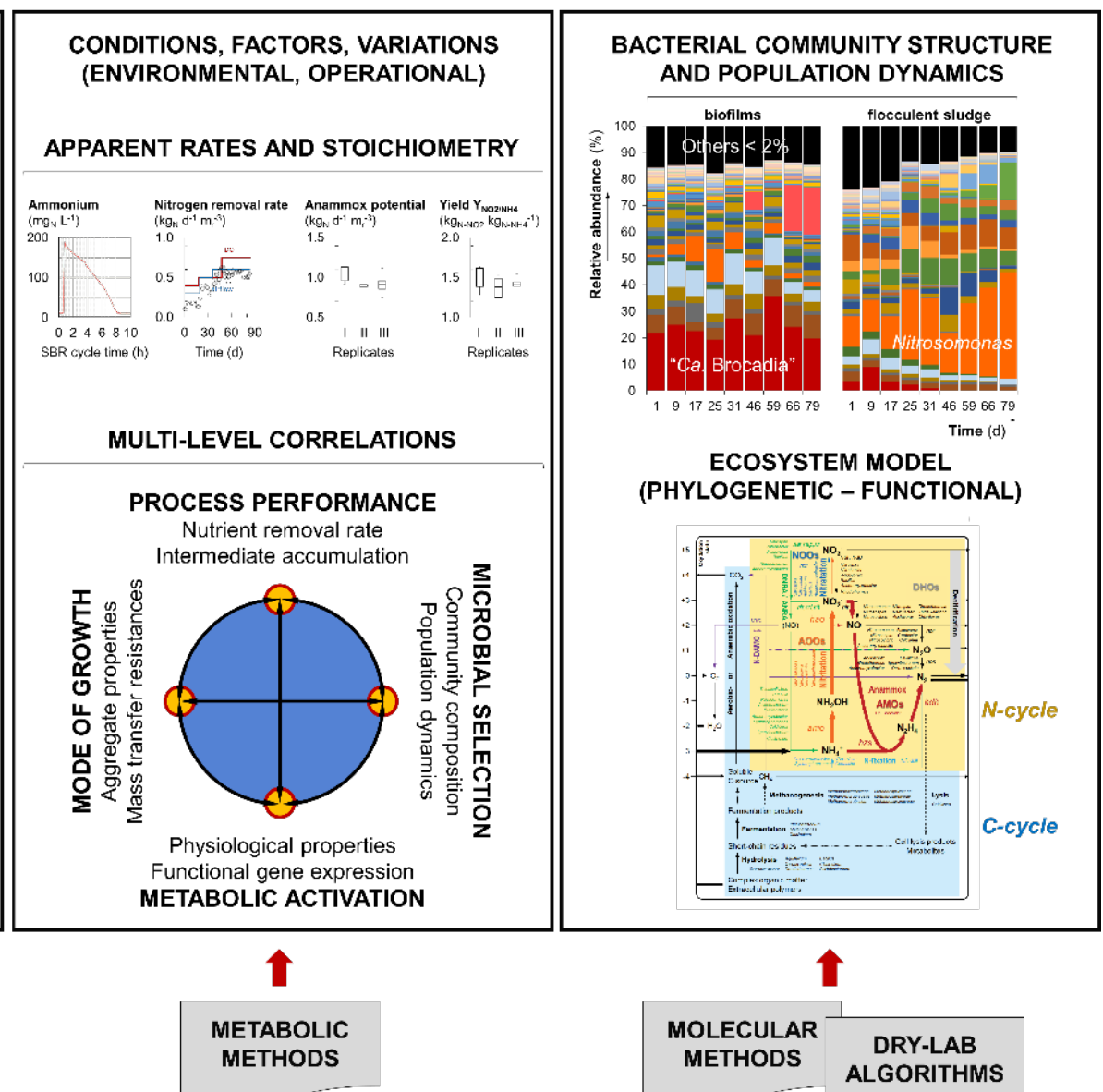

Figure 6. A systems microbiology framework in PN/A process engineering. Multi-level relationships from process boundaries to microbiome, bioaggregate, functional features, and metabolic features in PN/A systems. In the systems microbiology approach, the bacterial microbiome is considered as the heart of the biosystem, responding to environmental and operational triggers in terms of microbial selection, and functional and metabolic activation or repression. Predominant populations and their underlying physiologies also determine the architecture of the bioaggregates that they generate, in conjunction with process conditions (Weissbrodt, et al., 2013). Molecular and numerical methods need to be adapted to the specific system of interest, whereas replicated processes provide additional power in the assessment of correlative responses. The signatures identified out of welldefined experimental designs can sustain the elaboration of feed-back and/or feed-forward operational and microbial community engineering strategies for the sake of more performant, resistant, and resilient open mixed-culture biological processes.

One should nonetheless realize that high-throughput and high-resolution analyses should not be sold as new promises for new engineering. They are meant for a detailed analysis and scientific investigation of microbiomes. Design and control of environmental biotechnologies will always mainly rely on stoichiometry and kinetics, simply. Breakthrough will be specifically made by systems microbiology if enabling to provide key information for process engineering that is not already covered by stoichiometry and kinetics.

\section{A systems-level guidance in $\mathbf{1 0}$ milestones to solve engineered microbiomes}

Systems microbiology and systems biology are unilaterally driven by research questions and hypotheses. The two fields slightly differ semantically and on their analytical targets. Systems microbiology aims to crack microbial communities beyond their meta-level to extract information of single microorganisms and their genomic entities. It raises questions on the populations present, their activities, the respective location of their activities, the impacts of the community on its environment, and the effects of a disturbance on the community 279. Systems biology studies biological systems by 
perturbing them systematically, tracking informational pathway responses, and integrating quantitative data toward the formulation of mathematical models to describe the distributed biosystem structure and quantitatively predict responses to perturbations $^{280}$.

A framework is elaborated here in 10 milestones to guide the collection of detailed information from engineered biological systems like PN/A at different metrics from macro to meso, micro, genetic, and metabolic scales, and to translate them into engineering concepts. This roadmap is formulated in a broader context to be applicable to any microbial ecosystem and environmental biotechnology application of interest. It can be used in education linking environmental biotechnology to systems microbiology 223,281 .

\subsection{Secure resources for systems microbiology and} engineering investigations

Combining systems microbiology and engineering requires equal allocation of funding, personnel and time resources for wet-lab and dry-lab molecular analyses and for bioreactor infrastructure and operation 220,282 . On genomics per se, sequencing costs decreased more rapidly than Moore's law down to as low as $0.02 \$ \mathrm{MB}^{-1}$ of DNA sequence, but the computational infrastructure required to store, maintain, transfer, mine, analyze, and interpret the data accounts for principal expenses ${ }^{283}$. The selection for the adequate wet-lab and dry-lab methods is made with a research question in mind. Since data collection is not the endpoint, dry-lab resources and workflows (computing clusters, experts, web-sharing) are anticipated on early basis to store, process, analyze and interpret datasets such as sequencing reads or microscopy digital images, prior to, e.g., multivariate numerical analyses and mathematical modelling.

4.2 Conceptualize the biological system to formulate the multi-level question

Systems-level investigations efficiently start by sketching the targeted microbial system. A simplified overview of functional guilds, key microbial populations, and metabolic conversions can be drawn by integrating background knowledge from literature. The ecosystem sketch provides a framework to formulate the multi-level research question and hypothesis (Fig. 2c). One challenge consists of converging the diversity of aforementioned factors within the optimal range: conditions such as microbial composition, biomass matrix or influent characteristics vary from report to report on top of the intrinsic complexity of the mixed-culture microbial processes.

\subsection{Measure the biosystem performance by quanti- tative biotechnology}

Quantitative biotechnological measurements of growth and turnovers are performed to capture the stoichiometry, thermodynamics and kinetics of the bioprocess. The system configuration is chosen according to research objectives from bench to pilot and full scales, with suspended, attached, or hybrid biomass, with synthetic or real feeds, and under defined or varying environmental conditions. Replicating biological systems is highly desirable for statistical power. Reactor start-up phases are of particular interest since this provides information on deterministic mechanisms of microbial selection, activation, and aggregation. The baseline metabolic performance under (pseudo) steady-state conditions is monitored in situ and ex situ from the liquid, off-gas, and solid (biomass) phases of the biosystem over several hydraulic and biomass retention times. Such quantitative information is efficiently integrated in and used to calibrate computational mathematical models to predict the performance of the biosystem under different process scenarii.

\subsection{Analyze the microbial community composition at high resolution}

Field guides ${ }^{94,224,225}$ have been made available to sample biomass and analyze the microbial community compositions in environmental engineering systems. Analytical awareness should be raised throughout protocols. Well-designed modifications of workflows are frequently required depending on specific experimental conditions, biological systems, bioaggregates, and microorganisms investigated.

Dual use of methods and cross-validation of analytical outputs is important to obtain a representative information from the biosystem. Each method is impacted by an own set of biases. The methods 
must be tested and validated upfront with the biological matrices of interest, before analyzing the full set of samples collected for time and/or geographical series over the system. Similar to analytical chemistry, quality control is crucial in all molecular and computational workflows. Careful attention should be allocated to sampling conditions and frequency, biological sample replication, pretreatment (e.g., without or with homogenization if spatial distribution across bioaggregates or solely relative abundances are meant to be measured) and storage depending on process studied and analytical targets, and all subsequent steps of the analytical procedure.

The combination of untargeted amplicon sequencing and targeted qFISH is efficient to obtain the community fingerprint, identify the predominant and low-abundance populations, and measure the relative abundance of populations. Amplicon sequencing is powerful to delineate overall microbial community compositions (bacteria, archaea, eukarya), using sets of universal primers along the 16S (Table 1 for bacteria) and/or 18S rRNA gene pools. Guilds or phylotypes of interest are targeted with specific probes accordingly. Preliminary information gained from marker-gene surveys on phylotypes composing the community guides the more quantitative detection of ribotypes of interest with qFISH and/or qPCR depending on required analytical sensitivities. Oligonucleotides are validated in silico and at wet lab for amplification (PCR) or hybridization (FISH) efficiencies and phylogenetic specificities (Table 1). The correspondence of results obtained by PCR-based and FISH-based is not always straightforward since these methods rely on different analytical principles targeting gDNA and rRNA, respectively.

Numerical ecology analyses involving multivariate and statistical methods can be used to structure, visualize and compare the microbial community datasets and draw correlations between population dynamics and regime shifts $50,118,214,284-288$. Collection of metadata on process conditions, operations, and performance parallel to sampling is crucial.

In the PN/A context, questions can be solved, e.g., on which populations form the core community of sidestream and mainstream PN/A processes, whether system configurations share a common microbiome, whether the PN/A microbiome differ from traditional BNR ecosystems, whether communities are composed of a highly diverse consortium or a low number of phylotypes, and which environmental and operational factors seem to impact microbial selection.

Localize populations of interest at biosystem and bioaggregate scales

Environmental biosystems are seldom composed of a uniform biomass. While under labs-cale condition specific types of bioaggregates can be tailored, pilot and full-scale systems are mostly hybrid. Differences in community compositions are displayed between the biofilms, granules and/or flocs present in the bioreactor $58,64,67,289-291$. These differences can be highlighted by molecular analyses after pragmatic collection of these different bioaggregate fractions from the biosystem. FISH can be combined with either epifluorescence microscopy (EFM) or confocal laser scanning microscopy (CLSM) to hybridize and visualize the microbial populations in the architecture of bioaggregates and biofilms. Cryosectioning provides a way to analyze the distribution of microbial populations across biofilm or granule cross-sections $87,115,292$. Different stainings and fluorescence lectin-binding analysis (FLBA) can be used to map the extracellular polymeric substances (EPS) surrounding the microorganisms ${ }^{87,293}$. Microbial niche establishment in bioaggregates and biofilms can be analyzed along chemical gradients of substrates and redox conditions measured with microsensors ${ }^{294,295}$.

In the context of PN/A, one can elucidate which biomass fractions are colonized by AOOs, AMOs, NOOs and DHOs, how deep do their populations sit within biological architectures, and whether biofilms and flocs display phylogenetic differentiation in hybrid systems.

\subsection{Elaborate a conceptual ecosystem model to pre- pare functional analyses}

Conceptual ecosystem models are efficient to rationalize microbiome signatures $50,223,273,296$. Amplicon sequencing datasets are meant to be used at high resolution to delineate the core microbiome of the biological system, and to identify the predominant and accompanying phylotypes forming functional guilds. The predominant phylotypes are rapidly attributed to major functional guilds according 
to general microbiology, biochemistry, and process knowledge. Metabolic information on flanking populations is gained from reference manuals and databases, while their function within microbiomes is seldom understood. Verstraete ${ }^{297}$ conceptualizes that the essential function of rare taxa ${ }^{298}$ is to connect the set of main metabolizing populations in the microbiome. Analytical methods to investigate such connectivity are needed.

The high sequencing resolution is harnessed to understand most of the architecture of the microbial network along guilds and populations identified together with their predicted function. Such a qualitative model provides an improved understanding of the structure of the biosystem. It provides a strong basis to further drive research questions and hypotheses at functional levels from community scale to single lineages. The structure can be enhanced by spatial localization over flocs and biofilms, and inside these bioaggregates. It supports validation of physiological and metabolic properties. The conceptual model of the PN/A ecosystem drafted here from bacterial and archaeal populations detected from sidestream and mainstream processes suggests a distributed network of microbial populations and metabolisms (e.g., nitrogen and carbon conversions) more complex than traditionally considered at engineering level (Fig. 7).

Numerous populations harbor putative genetic capabilities for nitrite reduction to nitric and nitrous oxides and dinitrogen. Pathways leading to undesirable $\mathrm{NO}$ and $\mathrm{N}_{2} \mathrm{O}$ intermediates should be investigated in these denitrifying populations ${ }^{101}$, besides AOOs and AMOs. Accompanying populations may also be involved in dissimilatory (DNRA) and assimilatory (ANRA) pathways of nitrate and nitrite reduction to ammonium, nitrogen fixation, and other nitrogen conversions.

\subsection{Use genome-centric metagenomics to genet- ically fingerprint the microbiome}

Higher resolution on the metabolic potentials of the main metabolizing populations and flanking populations can be retrieved from single-lineage genomes binned from metagenomes 43,299,300. With the democratization of sequencing and bioinformatics, genome-based microbial and functional ecology becomes a key discipline to investigate mi- crobial communities ${ }^{120,265}$. Metagenomes of the biomasses are sequenced at different time and/or geographical points. Genomic DNA (gDNA) is extracted. Different methods of DNA extraction can be used on the same samples to generate a synthetic shift in community compositions, that is useful to isolate the single-lineage genomes by differentialcoverage binning ${ }^{43}$. The single-lineage genomes retrieved for populations of interest are annotated for their functional genetic signatures ${ }^{299}$. They can used to formulate genome-scale or genome-based metabolic models from single populations ${ }^{301,302}$. The individual genome-based models of different populations can be aggregated to predict the interactions between populations in the metabolic network of the microbiome ${ }^{91,303}$.

In the PN/A context, genomes from AOOs, AMOs, NOOs, DHOs and accompanying rare taxa can be retrieved from the metagenome, annotated and mapped to identify their metabolic traits and interaction potential. These genetic fingerprints form also important references for the mapping of functional multi-omics datasets.

\subsection{Emphasize the core metabolic functions of pop- ulations of interest by ecophysiology}

Functional and metabolic traits can be validated with ecophysiology methods 29,246,304,305. MARFISH and SIP techniques can be applied at an early stage in parallel to amplicon sequencing to detect if metabolisms of interest are present in the community. Sequencing following SIP and MAR-FISH help to elucidate specific activities together with taxonomic information. Such functional information can be used to delineate whether these populations exert an activity that may impact the process efficiency and stability. After collection from the bioreactor, biomass can be incubated with labelled substrates (either stable isotopes in SIP or radiolabeled in MAR) to track their assimilation into informational cellular macromolecules like nucleic acids (DNA, RNA), proteins, polysaccharides, lipids or other storage polymers like poly- $\beta$ hydroxyalkanoates. Higher-resolution analyses by SIMS or NanoSIMS can be used to track metabolic features of individual populations in situ ${ }^{246,306}$. In the PN/A context, the specific metabolic functions and side metabolisms of predominant populations of AOOs, AMOs, NOOs and DHOs and flanking phylotypes can be unraveled beyond the overall functional potential of the biomass. 


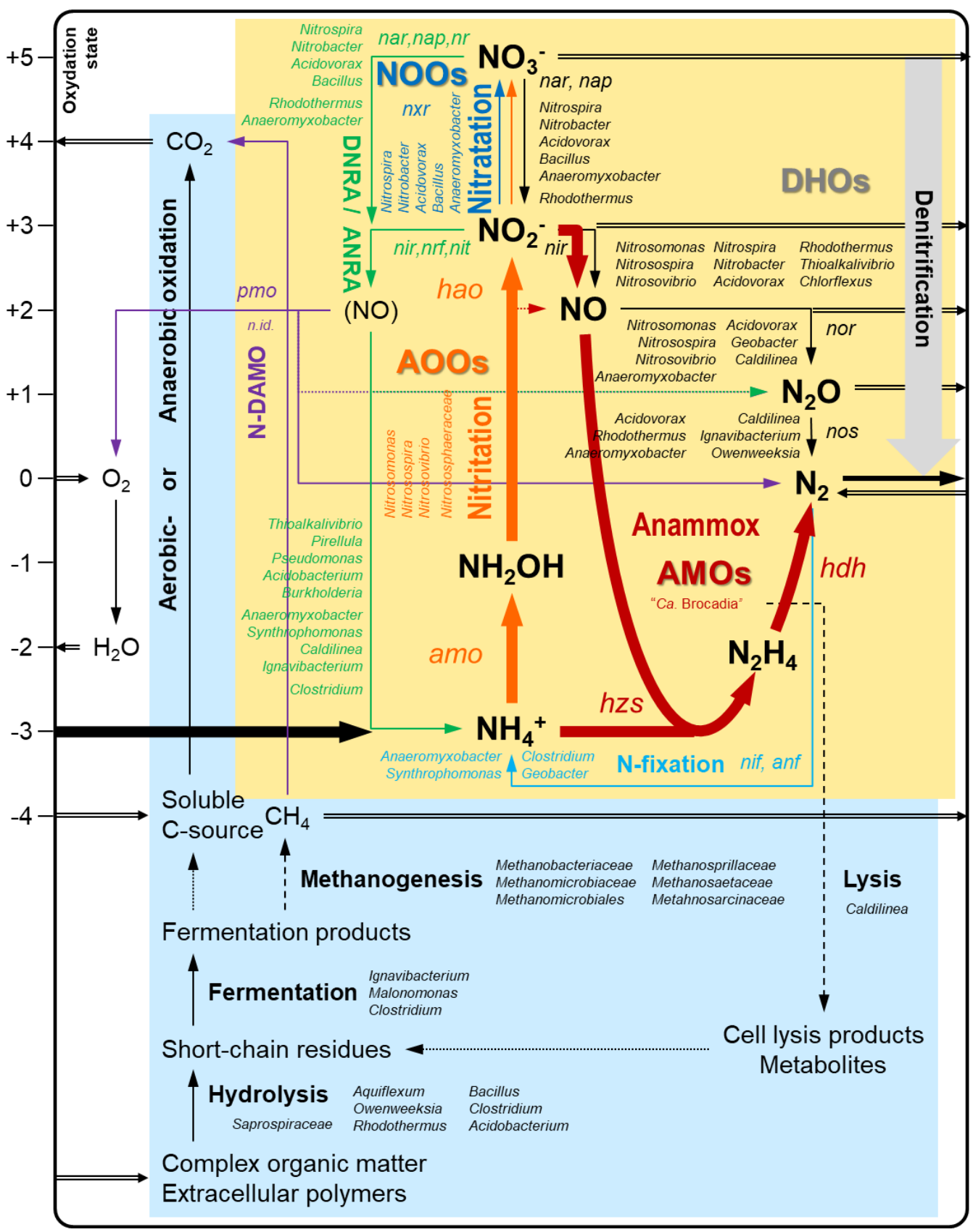

Figure 7. The conceptual model of the PN/A ecosystems along the underlying nitrogen (yellow) and carbon (blue) cycles as basis for functional analyses. This qualitative model was built based on the predominant phylotypes detected by 16S rRNA gene-based amplicon sequencing in the bacterial and archaeal community datasets of sidestream and mainstream systems. It provides higher resolution on the tentative phylogenetic and metabolic networks inside PN/A microbiomes. Ammonium $\left(\mathrm{NH}_{4}{ }^{+}\right)$enters the biosystem with the wastewater (thick black arrow). It gets partially oxidized aerobically into nitrite $\left(\mathrm{NO}_{2}{ }^{-}\right)$via hydroxylamine $\left(\mathrm{NH}_{2} \mathrm{OH}\right)$ by the guild of aerobic ammonium oxidizing-organisms (AOOs) that comprises bacteria and archaea (thick red arrows). The second half of the ammonium load gets oxidized by nitrite via nitric oxide (NO) into dinitrogen ( $\left.\mathrm{N}_{2}\right)$ by the guild of anaerobic ammonium-oxidizing organisms (AMOs). If an excess of oxygen is transferred into the bulk liquid phase, then aerobic nitriteoxidizing (NOOs) competitors unfavorably kick in the system at the expense of AMOs (green arrow). AMOs are also known to partly produce nitrate $\left(\mathrm{NO}_{3}{ }^{-}\right)$according to their stoichiometry of microbial growth. Denitrifying heterotrophic organisms (DHOs) may compete for nitrite with AMOs in the presence of a substantial amount of readily biodegradable organic matter (>> 0.5 $\left.\mathrm{g}_{\mathrm{COD}} \cdot \mathrm{g}_{\mathrm{N}}{ }^{-1}\right)$. The denitrification pathway goes from nitrite to nitric oxide, nitrous oxide $\left(\mathrm{N}_{2} \mathrm{O}\right)$ and dinitrogen. In the presence of a limiting amounts of COD, denitrifiers only achieve a partial pathway leading to emission of $\mathrm{NO}$ and $\mathrm{N}_{2} \mathrm{O}$ in the off-gas. AOOs and putatively AMOs may contribute to the formation of these unfavorable greenhouse compounds. NO is the central intermediate. The conceptual ecosystem model displays that the network of the nitrogen and carbon cycles of PN/A microbial systems is more complex that traditionally considered at process level. Other populations that may harbor functional potential for nitrogen dis- 
similatory (DNRA) and assimilatory (ANRA) nitrate and nitrite reduction to ammonium fixation, as well as nitrogen fixation. Populations that may harbor nitrite-driven anaerobic methane oxidative (N-DAMO) properties were not detected here, but have been in some other studies. The carbon cycle can be triggered by readily biodegradable organic solutes present in the feed (e.g., in main stream if no or inefficient A-stage) or by the presence of residual complex organic matter (e.g., in side stream after anaerobic digestion) or by the decay of biomass. Hydrolytic, fermentative, and methanogenic pathways may occur depending on biomass configurations (e.g., biofilms) and oxygenation levels. Dissolved methane formed or originating from the anaerobic digester centrate may then be oxidized by N-DAMO organisms in the presence of nitrite, with NO as central intermediate; oxygen is produced. The metabolic pathways are oriented along the oxidation states of the dissolved substrates (scale on left hand side). The catabolic enzymes involved are displayed along with the guilds of sequenced microbial populations.

4.9 Analyze the expressed metabolic functions and regulation with high throughput

Given that such analytical resources are accessible and affordable for the project, engineered biological systems should be investigated by starting out broad using shotgun methods at the nucleotide level using gDNA-based genome-centric metagenomics and mRNA-based metatranscriptomics, and zooming into the community to narrow down the research questions toward elucidation of specific metabolic pathways of interest using metaproteomics and metabolomics 128,133,262,307,308.

Experiments are designed carefully according to research questions. Multi-factorial designs and numerical ecology methods ${ }^{50,121}$ can be implemented to screen for factors in a limited number of runs. This can lead to an unprecedented understanding of microbiome responses to varying conditions along the system performance.

After having sequenced the metagenome and retrieved single-lineage genome references from the ecosystems, the metatranscriptome and metaproteome of the biomass can be sequenced ${ }^{133,309-314}$ under baseline conditions to provide the distribution of the normally-expressed metabolic functions over the community prior to analyzing the transcriptional and enzymic regulation of the community and of the populations under transient, dynamic and disturbed conditions by switching from equilibrium states. Metabolomics and fluxomics using labelled substrates and mass spectrometry can track and quantitatively validate switches in metabolic pathways $109,315,316$.

Depending on the depth and quality of mapping databases, multiple questions can be solved in the PN/A context, e.g., on whether metabolic functions are distributed over the populations and the guild of the microbiome, whether certain organisms har- bor potential for the metabolism of organic substrates or xenobiotics, whether exotic metabolisms such as detoxification pathways can be predicted, whether the bacterial community responds to operational and environmental variations, whether populations of interest are sensitive to specific factors, and whether $\mathrm{NO}$ and $\mathrm{N}_{2} \mathrm{O}$ formation pathways can be related to phylotypes.

\subsection{Rationalize biosystem signatures and ecological principles into biotechnology}

Systems-level signatures obtained from PN/A biocoenoses need to be consistently integrated into meaningful concepts for engineering. This can go via their translation into applied methodologies for their management via the control of operational parameters. Systems microbiology will seldom solve the engineering per se. Design of bioprocesses is mainly driven by stoichiometry and kinetics. However, systems microbiology provides key insights into the microbial composition, metabolic functionalities, and balance of interaction within the microbiome.

By adopting experimental and on-site investigation designs that embrace both quantitative process engineering and systems microbiology analyses one will be able to correlate yields and rates to more detailed insights onto the distributed metabolic functionalities across key microbial populations present in the process microbiome. Under the event of process disturbances, one will be able to identify which microbial populations and functionalities have been unfavorably impacted. This can cover, e.g., conditions that select and activate, or repress and outcompete, populations of interest for the process and that are required to maintain an active and cooperative microbial community. Deterministic and probabilistic constraints are needed to maintain a balance between predominant and flanking populations for a stable performance of the biological system. 
Systems microbiology analyses can run by: $(i)$ collecting and initial sample of biomass from the system of interest, extracting gDNA, characterizing the microbial compositions by amplicon sequencing and the genetic fingerprints of the key microorganisms present in the biomass by genome-centric metagenomics; (ii) sampling the biosystem on regular basis for either mRNA or protein extractions and metatranscriptomics and/or metaproteomic measurements of the variations in abundances of transcripts and/or enzymes involved in the conversions of interest. The single-lineage genomes retrieved from the metagenomes form important bases for the annotations of the metatranscriptomes and metaproteomes. These data can (iii) be confronted to process operation and environmental conditions and the quantitative measurements of conversions, yields and rates.

Multifactorial experimental/investigation designs will be efficient to aggregate process and higher resolution molecular datasets to identify which factor exert the main effect on the measured responses across scales ${ }^{121}$. The reunion of data will be powerful to derive theories on the microbial system functionality toward the delineation of concepts for robust process operation to, e.g., overcome unfavorable emission of, e.g., $\mathrm{N}_{2} \mathrm{O}$, or to preferentially select besides PN/A for an active guild of denitrifiers specialized in $\mathrm{N}_{2} \mathrm{O}$ reduction ${ }^{101}$. Factors should be mastered to prevent shunts in metabolic pathways in specific populations that lead to unfavorable emission of $\mathrm{NO}$ and $\mathrm{N}_{2} \mathrm{O}$. System loading strategies to prevent inhibitory effects, and parameter variations should be minimized to allow for a reliable performance of the microbial system.

\section{Outlook: Generating consensus between sys- tems (micro)biology and engineering}

The discovery from engineered environments of novel microorganisms performing anammox metabolisms has revolutionized concepts of nitrogen removal toward the achievement of improved energy efficiency at plant level. The field of PN/A is booming from sidestream to mainstream applications. The achievement of reliable treatment performances nonetheless remains a challenge for both high-strength and low-strength nitrogenous wastewaters. After the early warnings on process failures made over the last decade, it is now time to recognize - and to put into application - that the efficiency of open mixed-culture environmental biotechnology systems such as PN/A requires good practices of microbial resource management by a full consideration of the intrinsic features of the underlying complex microbial communities. The microbial ecology science offers an arsenal of molecular methods that can be applied to characterize microbiomes with different degrees of resolution, thus following on the research questions defined upfront. In a crystal ball vision, a pragmatic approach of systems microbiology is required to diagnose and squeeze most of the informational signatures from the population and metabolic networks of PN/A microbial ecosystems and to rationalize it in their engineering context. This sustains an improved understanding of their behavior and delineation of applied strategies for enhanced performance and remedial action. The here elaborated "process ecogenomics" framework sustain rational investigations at the essence of the biosystem by thinking beyond the guild level.

In this article we addressed most of open aspects related to PN/A studies. However, one aspect is still missing: generating the consensus between process engineering and systems (micro)biology. A consensus cannot be generated, if one of the primary goals of any new study is to make a point that authors understand PNA systems better than previous research studies. Our "process ecogenomics framework" emphasize on the need for $(i)$ being meticulous about experimental design and (ii) integrating microbial ecology into process engineering. This becomes possible only when the research community starts considering the inherent differences between studies and performing direct comparison only if carried out on the same biological system. Whether it is process engineering or microbial ecological studies, one thing that is still difficult to attain is a consensus, since the majority of PN/A studies compare results with one another, but not systematically. This framework can also lay ground to establish a consensus of systematic and comparable reactor operations and analytical methods to include all phases in process ecogenomics.

We stress here that there is still a long way to go, which means that we need to perform research that complements each other group foci. In other words, it becomes essential that, as soon as different results are obtained between works, we focus on answer "Why?" beyond solely stating differences and 
concluding with general remarks. The different labs own extremely different experiences, but cannot find reasons for most of reported differences.

Hence, we advocate the need to establish research $\&$ application consortia for the integration of a multidisciplinary framework of process ecogenomics. This provides a forum to address questions that require more resources than one organization alone could handle and to engage many research groups and practitioners from different disciplines. Such consortium-based research is well suited for tackling some of the questions encountered in process ecogenomics. The most significant difference compared to other environmental biotechnology processes such as conventional nitrification and denitrification is, that PN/A systems encompass a microbial interaction which includes competition. PN/A is an attempt to establish a fine-scale biological process with maximum efficiency in an open environment. Integrating ecological data with process engineering at individual labs do not provide enough confidence in PN/A process.

High-level achievements will soon result from close scientific assembly from PN/A to mixed-culture microbial systems in general. The advent of novel workflows in process engineering science and environmental systems (micro)biology deliver new ways for high-resolution investigation of microbial ecosystems. Reuniting specialists into consortia will lead to higher-level and reproducible achievements. It is about reproducibility, which leads to sustainability.

\section{Conclusion}

Environmental biotechnologies rely on the understanding, engineering and management of microbial communities. Collectively, from this in-depth critical review across the engineering and systems microbiology of PN/A mixed-culture processes, we conclude that:

1. A detailed systems-level understanding of microbial networks, such as propelled by our "process ecogenomics" approach, can drive the definition of ecosystem models and functional analyses.

2. Community systems microbiology fosters the collection of scientific information at high resolution from populations to metabolic functions and their distributed interactions across complex and sensitive, engineered microbiomes like PN/A.

3. A specific interaction should be shaped between process engineering and systems microbiology to drive the definition of common investigation lines.

4. While new-generation methods are often sold as new promises for engineering, engineering practice will only embrace them if generating new knowledge and concepts that are not already caught by stoichiometry and kinetics.

5. Managing open mixed-culture systems like PN/A is not just about big data, but definitely about good data that can be transformed into theory and designs.

Targeted analyses of systems microbiology provide detailed insights on the microorganisms, their functionalities, and regulations of their metabolisms distributed across the microbiome and that should then be confronted to process metadata and quantitative measurements of yields and rates to identify key operational and environmental factors that primarily impact the selection and activation of populations as well as the balance of their interaction in the microbiome. Definitely, systems microbiology cannot be sold as new promise for design. It provides all the necessary, detailed scientific and mechanistic understanding of the metabolisms distributed across the microbial populations of the community. Confrontation of process and molecular data will lead to an informed management of identified factors and process variations that impact the metabolic functionality of the microbial system. On a continuum from life and physical science, this is how systems microbiology understanding can be translated to make an impact to engineer microbial communities and manage them via process design and operation. 
Weissbrodt, Wells, Laureni, Agrawal, Goel, Russo, Men, Johnson, Christensson, Lackner, Joss, Lund Nielsen, Bürgmann and Morgenroth (2020) Systems Microbiology and Engineering of Aerobic-Anaerobic Ammonium Oxidation | ChemRxiv preprint | 25 of 34

\section{Glossary}

\section{Key terminology used in systems microbiology and engineering}

Amplicon sequencing: Molecular method that is progressively becoming established for the profiling of microbial communities. Hypervariable regions of the $16 \mathrm{~S}$ rRNA gene are amplified by PCR using a combination of two oligonucleotides (also called primers) that bind to the double strand of DNA. The resulting pools of amplicons are sequenced with high throughput. Amplicons sequencing allows for the screening of full bacterial community compositions. "Universal" primers are used for the broadest possible coverage of the bacterial community. This method can also be used to cover the other kingdoms of archaea and eukarya; other primer pairs are needed to these ends.

Bioinformatics: Computational discipline used to develop algorithms, to process and to investigate the essence of the information comprised in big digital datasets gained from molecular measurements of biological systems (here, microbial communities).

Community systems microbiology (also termed ecogenomics): Science of microbial communities that arose from molecular biology and environmental genomics advances made in the field of microbial ecology, and that targets the investigation of microbial interactions in microbial communities. This science aims microorganisms and their genomes as critical units of organization of the microbial community. It aims to go beyond the meta-feature (i.e., community as a whole) of microbial communities toward the obtaining of single-lineage genomes and (functionally validated) metabolic models. Genomic, metabolic, and ecophysiology information gained from the individual populations composing the microbial community are then re-aggregated toward elucidation of the overall functioning and performance of the community.

Conceptual ecosystem model: Conceptual representation of the microbial and functional ecology of the microbial ecosystem of an environmental biotechnology process, and in which populations and their putative (or validated) metabolic functions are displayed.

Candidatus organism: Microbial populations that have not yet been isolated, cultivated and metabolically characterized in pure culture but that differ in genetic information from reference isolates are denominated was candidate genera or species. Microbiology systematics impose their denomination as "Candidatus ..." such as for the candidate anammox specie "Candidatus Brocadia fulgida" (note the only official writing).

Database: Reference sequences obtained from the sequencing of genes (or gene fragments) and genomes of known organisms are compiled in on-line databases that can be used in computational algorithms for the mapping of sequences obtained by from the biological samples of interest.

Ecophysiology methods: Microbial ecology methods that are used to examine the metabolic functionality of microorganisms of interest.

Fluorescence in situhybridization (FISH): Molecular method that is widespread for the specific detection of target microorganisms in microbial communities using an oligonucleotide that binds to the single-stranded ribosomal RNA (rRNA), by combination with a fluorescence microscopy method (e.g., epifluorescence microscope, confocal laser scanning microscope).

Functional ecology: Study of the metabolic diversity of microorganisms present inside microbial communities, and the interrelationship between environmental factors and phenomena of metabolic activation.

Genome-centric metagenomics: Retrieving, assembly and annotation of genomes of single population out of metagenomes of sludges and biomasses. The individual genomes are the central functional units of the microbiomes. They serve as references for mapping of functional meta-omics datasets and for the development of genome-scale or genome-based metabolic models to predict metabolic functions of populations. Genomic information of individual populations can be re-aggregated at microbiome level.

Informational molecules: Biological molecules that carry the genetic and metabolic information of microbial cells, namely DNA, RNA, proteins, and that are targeted in ecogenomic approaches.

Macro-, meso-, micro-, molecular, and metabolic scales: The five different scales that are investigated and aimed to be associated in process ecogenomic approaches to understand, anticipate and control the response and performance of the biological system of interest.

Metabolic methods: Analytical methods for the characterization of the metabolism of microorganism. Metabolic analyses are primarily performed by following the evolutions of the concentrations of substrates, metabolites, and products involved in the microbial metabolisms.

Meta-omics: New-generation methods based on high-throughput sequencing of informational molecules (metagenomics: gDNA, metatranscriptomics: mRNA, metaproteomics: proteins, metabolomics: metabolites) that can be extracted from 
Weissbrodt, Wells, Laureni, Agrawal, Goel, Russo, Men, Johnson, Christensson, Lackner, Joss, Lund Nielsen, Bürgmann and Morgenroth (2020) Systems Microbiology and Engineering of Aerobic-Anaerobic Ammonium Oxidation | ChemRxiv preprint | 26 of 34

microbial cells forming the microbial community. The molecular information contained in the microbial community is considered as hole in a first step, prior to isolation of molecular information specific to single lineages of interest using bioinformatics.

Microbial community (also termed microbiome): Set of microbial guilds.

Microbial community engineering: Discipline at the frontier of microbial ecology, environmental biotechnology and process engineering that aim to engineer the characteristics of microbial communities by engineering operational conditions that select for sets of microorganisms of interest useful for the biotechnology service within the broader microbial community continuum.

Microbial diversity: Range of different kinds of microorganisms within the kingdoms of bacteria, archaea, and eukarya, and that differ by their morphologies, physiologies, and cellular metabolisms, by their ecological distributions and activities, and by their genomic characteristics.

Microbial ecology: Study of the interrelationships between microorganisms and their environments.

Microbial ecosystem: Microbial communities form ecosystems in which the individual populations develop interactions (e.g. symbiotic, competitive, etc.). These interactions can lead to modifications of the characteristics of the ecosystem.

Microbial guild: Group of metabolically-related populations that share the same functions.

Microbial population: Functional unit of an individual microorganism with unique metabolic properties.

Microbial resource management: Discipline close to or complementary to microbial community engineering that aim to define strategies to manage the microbial resource (i.e., by analogy to human resource management) inside microbial communities of engineered processes.

Microbial selection: Engineering process that aim to apply specific conditions that select and enrich for the microorganism of interest inside the microbial community.

Molecular methods: Molecular biology methods target informational molecules originating from the functioning of microorganisms (i.e. DNA-, RNA-, protein-based).

Neutral effects: Stochastic/probabilistic phenomena of invasion and extinction that govern variations in microbial community compositions under pseudo steady-state conditions on the long run of environmental biotechnology processes, and that oppose to deterministic phenomena of microbial selection.

Open mixed-culture microbial processes: Environmental biotechnology process that functions with a complex microbial community under non-axenic conditions (i.e., by opposition to sterile pure-culture processes).

Partial nitritation and anammox: Engineering terminology for the combination of microbial processes of aerobic and anaerobic ammonium oxidation. One half of the ammonium load is converted aerobically into nitrite by the guild of aerobic ammonium-oxidizing organisms (AOOs), and the second half of the ammonium load get oxidized anaerobically (or anoxically in the engineering terminology) into dinitrogen by the guild of anaerobic ammonium-oxidizing organisms (AMOs) that use nitrite as terminal electron acceptor.

Physical models: Experimental system used to study research questions and test hypotheses on the metabolism of microorganisms. Namely bioreactors in the field of environmental biotechnology.

Process ecogenomics: Integrative discipline and terminology proposed here for the association of process engineering and ecogenomics in scientific investigations conducted in the field of environmental biotechnology.

Process ecologists: Professional discipline from educational program of environmental sciences and engineering and whose duty target the design of environmentally safe and healthy industrial processes. This discipline can be translated for the field of environmental biotechnology for professionals who will master the health state and performance of mixed-culture microbial processes using process ecogenomics approaches. 


\section{Acknowledgements}

DGW was supported by the Swiss National Science Foundation grant no. 151977 and by start-up fund from the TU Delft Department of Biotechnology. This work was further supported by internal funds (EM) at ETH Zürich and Eawag.

\section{Author contributions}

DGW conceptualized this critical review in close interaction with EM, wrote the manuscript and crafted artworks, with inputs, edits and critical feedbacks from all contributors based on collaborations launched on the quest for systems microbiology and engineering of PN/A.

\section{Conflict of interest statement}

The authors declare no conflict of interest.

\section{References}

1 Galloway, J. N. et al. Transformation of the nitrogen cycle: Recent trends, questions, and potential solutions. Science 320, 889-892, doi:10.1126/science.1136674 (2008).

2 Delwiche, C. C. \& Steyn, P. L. Nitrogen Isotope Fractionation in Soils and Microbial Reactions. Environ. Sci. Technol. 4, 929-935, doi:10.1021/es60046a004 (1970).

3 McCarty, P. L., Bae, J. \& Kim, J. Domestic wastewater treatment as a net energy producer-can this be achieved? Environ. Sci. Technol. 45, 7100-7106, doi:10.1021/es2014264 (2011).

4 Curtis, T. P. \& Sloan, W. T. Exploring microbial diversity - A vast below. Science 309, 1331-1333 (2005).

5 Ahn, Y. H. Sustainable nitrogen elimination biotechnologies: A review. Process Biochemistry 41, 1709-1721, doi:10.1016/j.procbio.2006.03.033 (2006).

6 Jetten, M. S. M. The microbial nitrogen cycle. Environ. Microbiol. 10, 2903-2909 (2008).

7 van Loosdrecht, M. C. M. \& Brdjanovic, D. Anticipating the next century of wastewater treatment. Science 344, 1452-1453 (2014).

8 Daims, H. et al. Complete nitrification by Nitrospira bacteria. Nature 528, 504-509, doi:10.1038/nature16461 (2015).

9 Fux, C. \& Siegrist, H. Nitrogen removal from sludge digester liquids by nitrification/denitrification or partial nitritation/anammox: Environmental and economical considerations. Water Sci. Technol. 50, 19-26 (2004)

10 Mulder, A. The quest for sustainable nitrogen removal technologies. Water Sci. Technol. 48, 67-75 (2003).

11 Sliekers, A. O. et al. Completely autotrophic nitrogen removal over nitrite in one single reactor. Water Res. 36, 2475-2482 (2002).

12 Joss, A. et al. Full-scale nitrogen removal from digester liquid with partial nitritation and anammox in one SBR. Environ. Sci. Technol. 43, 5301-5306 (2009).

13 Fux, C., Boehler, M., Huber, P., Brunner, I. \& Siegrist, H. Biological treatment of ammonium-rich wastewater by partial nitritation and subsequent anaerobic ammonium oxidation (anammox) in a pilot plant. J. Biotechnol. 99, 295-306 (2002).

14 Broda, E. Two kinds of lithotrophs missing in nature. Z. Allg. Mikrobiol. 17, 491-493 (1977).
15 Thamdrup, B. \& Dalsgaard, T. Production of N(2) through anaerobic ammonium oxidation coupled to nitrate reduction in marine sediments. Appl. Environ. Microbiol. 68, 1312-1318 (2002).

16 Mulder, A., van de Graaf, A. A., Robertson, L. A. \& Kuenen, J. G. Anaerobic ammonium oxidation discovered in a denitrifying fluidized bed reactor. FEMS Microbiol. Ecol. 16, 177-184 (1995).

17 Siegrist, H., Reithaar, S., Koch, G. \& Lais, P. Nitrogen loss in a nitrifying rotating contactor treating ammonium-rich wastewater without organic carbon. Water Sci. Technol. 38, 241-248, doi:10.1016/S0273-1223(98)00698-2 (1998).

18 van de Graaf, A. A. et al. Anaerobic oxidation of ammonium is a biologically mediated process. Appl. Environ. Microbiol. 61, 12461251 (1995).

19 Strous, M. et al. Missing lithotroph identified as new planctomycete. Nature 400, 446-449, doi:10.1038/22749 (1999).

20 Kuypers, M. M. et al. Massive nitrogen loss from the Benguela upwelling system through anaerobic ammonium oxidation. Proc. Natl. Acad. Sci. U. S. A. 102, 6478-6483, doi:10.1073/pnas.0502088102 (2005).

21 Egli, K. et al. Enrichment and characterization of an anammox bacterium from a rotating biological contactor treating ammoniumrich leachate. Arch. Microbiol. 175, 198-207 (2001).

22 Corominas, L. et al. New framework for standardized notation in wastewater treatment modelling. Water Sci. Technol. 61, 841-857 (2010).

23 Lackner, S. et al. Full-scale partial nitritation/anammox experiences An application survey. Water Res. 55, 292-303, doi:10.1016/j.watres.2014.02.032 (2014).

24 Strous, M., van Gerven, E., Zheng, P., Kuenen, J. G. \& Jetten, M. S. M. Ammonium removal from concentrated waste streams with the anaerobic ammonium oxidation (anammox) process in different reactor configurations. Water Res. 31, 1955-1962 (1997).

25 van Loosdrecht, M. C. M. \& Salem, S. Biological treatment of sludge digester liquids. Water Sci. Technol. 53, 11-20 (2006).

26 Bernet, N. \& Beline, F. Challenges and innovations on biological treatment of livestock effluents. Bioresour. Technol. 100, 5431-5436, doi:10.1016/j.biortech.2009.02.003 (2009).

27 Jenni, S., Vlaeminck, S. E., Morgenroth, E. \& Udert, K. M. Successful application of nitritation/anammox towastewater with elevated organic carbon to ammonia ratios. Water Res. 49, 316-326 (2014).

28 Wett, B. et al. Going for mainstream deammonification from bench to full scale for maximized resource efficiency. Water Sci. Technol. 68, 283-289 (2013).

29 Laureni, M. et al. Activity and growth of anammox biomass on aerobically pre-treated municipal wastewater. Water Res. 80, 325-336, doi:10.1016/j.watres.2015.04.026 (2015).

30 Lotti, T. et al. Pilot-scale evaluation of anammox-based mainstream nitrogen removal from municipal wastewater. Environ. Technol. 36, 1167-1177, doi:10.1080/09593330.2014.982722 (2015).

31 De Clippeleir, H. et al. One-stage partial nitritation/anammox at $15^{\circ} \mathrm{C}$ on pretreated sewage: Feasibility demonstration at lab-scale. Appl. Microbiol. Biotechnol. 97, 10199-10210 (2013).

32 Gilbert, E. M. et al. Low temperature partial nitritation/anammox in a moving bed biofilm reactor treating low strength wastewater. Environ. Sci. Technol. 48, 8784-8792 (2014).

33 Wett, B. et al. Expanding DEMON Sidestream Deammonification Technology Towards Mainstream Application. Water Environ. Res. 87, 2084-2089, doi:10.2175/106143015x14362865227319 (2015).

34 Hoekstra, M., de Weerd, F. A., Kleerebezem, R. \& van Loosdrecht, M. C. M. Deterioration of the anammox process at decreasing temperatures and long SRTs. Environ. Technol. 39, 658-668, doi:10.1080/09593330.2017.1309078 (2018).

35 Cao, Y., van Loosdrecht, M. C. M. \& Daigger, G. T. Mainstream partial nitritation-anammox in municipal wastewater treatment: status, bottlenecks, and further studies. Appl. Microbiol. Biotechnol. 101, 1365-1383, doi:10.1007/s00253-016-8058-7 (2017).

36 Agrawal, S., Seuntjens, D., Cocker, P., Lackner, S. \& Vlaeminck, S. E. Success of mainstream partial nitritation/anammox demands integration of engineering, microbiome and modeling insights. Curr. Opin. Biotechnol. 50, 214-221, doi:10.1016/j.copbio.2018.01.013 (2018). 
37 Chang, J., Lee, W. C. \& Yoon, S. Energy consumptions and associated greenhouse gas emissions in operation phases of urban water reuse systems in Korea. Journal of Cleaner Production 141, 728-736, doi:10.1016/j.jclepro.2016.09.131 (2017).

38 Joss, A. et al. Combined nitritation-anammox: Advances in understanding process stability. Environ. Sci. Technol. 45, 9735-9742 (2011).

39 Fux, C., Huang, D., Monti, A. \& Siegrist, H. Difficulties in maintaining long-term partial nitritation of ammonium-rich sludge digester liquids in a moving-bed biofilm reactor (MBBR). Water Sci. Technol. 49, 53-60 (2004).

40 Wett, B. et al. Syntrophy of aerobic and anaerobic ammonia oxidisers. Water Sci. Technol. 61, 1915-1922, doi:10.2166/wst.2010.969 (2010).

41 Weissbrodt, D. G. et al. Multilevel correlations in the biological phosphorus removal process: From bacterial enrichment to conductivity-based metabolic batch tests and polyphosphatase assays. Biotechnol. Bioeng. 111, 2421-2435, doi:10.1002/bit.25320 (2014).

42 Kuenen, J. G. Anammox bacteria: From discovery to application. Nat. Rev. Microbiol. 6, 320-326 (2008).

43 Albertsen, M. et al. Genome sequences of rare, uncultured bacteria obtained by differential coverage binning of multiple metagenomes. Nat. Biotechnol. 31, 533-538 (2013).

44 Dicke, M., van Loon, J. J. \& de Jong, P. W. Ecology. Ecogenomics benefits community ecology. Science 305, 618-619, doi:10.1126/science.1101788 (2004).

45 Chapman, R. W., Robalino, J. \& Trent, H. F., 3rd. EcoGenomics: analysis of complex systems via fractal geometry. Integr. Comp. Biol. 46, 902-911, doi:10.1093/icb/icj049 (2006).

46 Nobu, M. K. et al. Microbial dark matter ecogenomics reveals complex synergistic networks in a methanogenic bioreactor. ISME J. 9, 1710-1722, doi:10.1038/ismej.2014.256 (2015).

47 Quince, C., Curtis, T. P. \& Sloan, W. T. The rational exploration of microbial diversity. ISME J. 2, 997-1006 (2008).

48 Graham, E. B. et al. Microbes as engines of ecosystem function: When does community structure enhance predictions of ecosystem processes? Front. Microbiol. 7, 214, doi:10.3389/fmicb.2016.00214 (2016).

49 Nielsen, P. H., Saunders, A. M., Hansen, A. A., Larsen, P. \& Nielsen, J. L. Microbial communities involved in enhanced biological phosphorus removal from wastewater - a model system in environmental biotechnology. Curr. Opin. Biotechnol. 23, 452-459 (2012).

50 Weissbrodt, D. G., Shani, N. \& Holliger, C. Linking bacterial population dynamics and nutrient removal in the granular sludge biofilm ecosystem engineered for wastewater treatment. FEMS Microbiol. Ecol. 88, 579-595, doi:10.1111/1574-6941.12326 (2014).

51 Vanwonterghem, I., Jensen, P. D., Ho, D. P., Batstone, D. J. \& Tyson, G. W. Linking microbial community structure, interactions and function in anaerobic digesters using new molecular techniques. Curr. Opin. Biotechnol. 27, 55-64, doi:10.1016/j.copbio.2013.11.004 (2014).

52 Lawson, C. E. et al. Common principles and best practices for engineering microbiomes. Nat. Rev. Microbiol. 17, 725-741, doi:10.1038/s41579-019-0255-9 (2019).

53 Rittmann, B. E. et al. A vista for microbial ecology and environmental biotechnology. Environ. Sci. Technol. 40, 1096-1103, doi:10.1021/es062631k (2006).

54 Verstraete, W. Microbial ecology and environmental biotechnology. ISME J. 1, 4-8 (2007).

55 Stahl, D. A. \& Wagner, M. The knowledge explosion in environmental microbiology offers new opportunities in biotechnology. Curr. Opin. Biotechnol. 17, 227-228 (2006).

56 Morgenroth, E. \& Milferstedt, K. Biofilm engineering: Linking biofilm development at different length and time scales. Reviews in Environmental Science and Biotechnology 8, 203-208 (2009).

57 Perez, J., Isanta, E. \& Carrera, J. Would a two-stage N-removal be a suitable technology to implement at full scale the use of anammox for sewage treatment? Water Sci. Technol. 72, 858-864, doi:10.2166/wst.2015.281 (2015).

58 Rodriguez-Sanchez, A. et al. Distribution and microbial community structure analysis of a single-stage partial nitritation/anammox granular sludge bioreactor operating at low temperature. Environ.
Technol. 37, 2281-2291, doi:10.1080/09593330.2016.1147613 (2016).

59 Laureni, M. et al. Mainstream partial nitritation and anammox: longterm process stability and effluent quality at low temperatures. Water Res. 101, 628-639 (2016).

60 Lackner, S., Welker, S., Gilbert, E. M. \& Horn, H. Influence of seasonal temperature fluctuations on two different partial nitritationanammox reactors treating mainstream municipal wastewater. Water Sci. Technol. 72, 1358-1363, doi:10.2166/wst.2015.301 (2015).

61 Piculell, M., Christensson, M., Jonsson, K. \& Welander, T. Partial nitrification in MBBRs for mainstream deammonification with thin biofilms and alternating feed supply. Water Sci. Technol. 73, 12531260, doi:10.2166/wst.2015.599 (2016).

62 Trojanowicz, K., Plaza, E. \& Trela, J. Pilot scale studies on nitritationanammox process for mainstream wastewater at low temperature. Water Sci. Technol. 73, 761-768, doi:10.2166/wst.2015.551 (2016).

63 Christensson, M., Ekström, S., Chan, A. A., Le Vaillant, E. \& Lemaire, R. Experience from start-ups of the first ANITA Mox Plants. Water Sci. Technol. 67, 2677-2684 (2013).

64 Veuillet, F. et al. Integrated fixed-film activated sludge ANITA ${ }^{\text {TMM Mox }}$ process - A new perspective for advanced nitrogen removal. Water Sci. Technol. 69, 915-922 (2014).

65 Corbalá-Robles, L., Picioreanu, C., van Loosdrecht, M. C. M. \& Pérez, J. Analysing the effects of the aeration pattern and residual ammonium concentration in a partial nitritation-anammox process. Environ. Technol. 3, 1-22, doi:10.1080/09593330.2015.1077895 (2015).

66 Volcke, E. I. P., Picioreanu, C., De Baets, B. \& van Loosdrecht, M. C. M. Effect of granule size on autotrophic nitrogen removal in a granular sludge reactor. Environ. Technol. 31, 1271-1280, doi:10.1080/09593331003702746 (2010).

67 Laureni, M. et al. Biomass segregation between biofilm and flocs improves the control of nitrite-oxidizing bacteria in mainstream partial nitritation and anammox processes. Water Res. 154, 104-116, doi:10.1016/j.watres.2018.12.051 (2019).

68 Lackner, S. \& Horn, H. Comparing the performance and operation stability of an SBR and MBBR for single-stage nitritation-anammox treating wastewater with high organic load. Environ. Technol. 34, 1319-1328 (2013).

69 Wells, G. F., Johnson, D. R., Buergmann, H., Weissbrodt, D. G. \& Morgenroth, E. in 15th International Symposium on Microbial Ecology (ISME15). (ed Kim et al.).

70 Wett, B. et al. Key parameters for control of DEMON deammonification process. Water Practice 1, 1-11 (2007).

71 Lotti, T., Kleerebezem, R., Abelleira-Pereira, J. M., Abbas, B. \& van Loosdrecht, M. C. Faster through training: The anammox case. Water Res. 81, 261-268, doi:10.1016/j.watres.2015.06.001 (2015).

72 van der Star, W. R. et al. The membrane bioreactor: a novel tool to grow anammox bacteria as free cells. Biotechnol. Bioeng. 101, 286294, doi:10.1002/bit.21891 (2008).

73 Wells, G. F. et al. in 9th IWA International Conference on Biofilm Reactors. (ed Soerensen et al.).

74 Masic, A. \& Eberl, H. J. A modeling and simulation study of the role of suspended microbial populations in nitrification in a biofilm reactor. Bull. Math. Biol. 76, 27-58, doi:10.1007/s11538-013-9898-2 (2014).

75 Hubaux, N., Wells, G. \& Morgenroth, E. Impact of coexistence of flocs and biofilm on performance of combined nitritation-anammox granular sludge reactors. Water Res. 68, 127-139, doi:10.1016/j.watres.2014.09.036 (2015).

76 Siegrist, H., Salzgeber, D., Eugster, J. \& Joss, A. Anammox brings WWTP closer to energy autarky due to increased biogas production and reduced aeration energy for N-removal. Water Sci. Technol. 57, 383-388 (2008).

77 Gao, H., Scherson, Y. D. \& Wells, G. F. Towards energy neutral wastewater treatment: methodology and state of the art. Environmental Science: Processes \& Impacts 16, 1223-1246, doi:10.1039/C4EM00069B (2014).

78 De Clippeleir, H. Microbial resource management of OLAND focused on sustainability, Ghent University, (2012).

79 Vlaeminck, S. E., De Clippeleir, H. \& Verstraete, W. Microbial resource management of one-stage partial nitritation/anammox. Microb. Biotechnol. 5, 433-448 (2012). 
80 Schmidt, I. et al. Aerobic and anaerobic ammonia oxidizing bacteria Competitors or natural partners? FEMS Microbiol. Ecol. 39, 175-181 (2002).

81 Perez, J., Lotti, T., Kleerebezem, R., Picioreanu, C. \& van Loosdrecht, M. C. Outcompeting nitrite-oxidizing bacteria in single-stage nitrogen removal in sewage treatment plants: a model-based study. Water Res. 66, 208-218, doi:10.1016/j.watres.2014.08.028 (2014).

82 Ma, B. et al. Suppressing nitrite-oxidizing bacteria growth to achieve nitrogen removal from domestic wastewater via anammox using intermittent aeration with low dissolved oxygen. Sci. Rep. 5, 13048, doi:10.1038/srep13048 (2015).

83 Ni, B. J., Joss, A. \& Yuan, Z. Modeling nitrogen removal with partial nitritation and anammox in one floc-based sequencing batch reactor. Water Res. 67, 321-329, doi:10.1016/j.watres.2014.09.028 (2014).

84 Helmer, C. et al. Single stage biological nitrogen removal by nitritation and anaerobic ammonium oxidation in biofilm systems. Water Sci. Technol. 43, 311-320 (2001).

85 Vlaeminck, S. E. et al. Aggregate size and architecture determine microbial activity balance for one-stage partial nitritation and anammox. Appl. Environ. Microbiol. 76, 900-909 (2010).

86 Vannecke, T. P., Wells, G., Hubaux, N., Morgenroth, E. \& Volcke, E. I. Considering microbial and aggregate heterogeneity in biofilm reactor models: how far do we need to go? Water Sci. Technol. 72, 1692-1699, doi:10.2166/wst.2015.389 (2015).

87 Weissbrodt, D. G., Neu, T. R., Kuhlicke, U., Rappaz, Y. \& Holliger, C. Assessment of bacterial and structural dynamics in aerobic granular biofilms. Front. Microbiol. 4, 175, doi:10.3389/fmicb.2013.00175 (2013).

88 Wells, G. F. et al. Comparing the resistance, resilience, and stability of replicate moving bed biofilm and suspended growth com-bined nitritation-anammox reactors. Environ. Sci. Technol. 51, 5108-5117 (2017).

89 Park, H., Sundar, S., Ma, Y. \& Chandran, K. Differentiation in the microbial ecology and activity of suspended and attached bacteria in a nitritation-anammox process. Biotechnol. Bioeng. 112, 272-279, doi:10.1002/bit.25354 (2015)

90 Filali, A., Bessiere, Y. \& Sperandio, M. Effects of oxygen concentration on the nitrifying activity of an aerobic hybrid granular sludge reactor. Water Sci. Technol. 65, 289-295 (2012).

91 Lawson, C. E. et al. Metabolic network analysis reveals microbial community interactions in anammox granules. Nat. Commun. 8, 15416, doi:10.1038/ncomms15416bag (2017).

92 Stokholm-Bjerregaard, M. et al. A critical assessment of the microorganisms proposed to be important to enhanced biological phosphorus removal in full-scale wastewater treatment systems. Front. Microbiol. 8, 718, doi:10.3389/fmicb.2017.00718 (2017).

93 Cao, Y. et al. The occurrence of enhanced biological phosphorus removal in a 200,000 m3/day partial nitration and Anammox activated sludge process at the Changi water reclamation plant, Singapore. Water Sci. Technol. 75, 741-751, doi:10.2166/wst.2016.565 (2017).

94 McIlroy, S. J. et al. MiDAS: the field guide to the microbes of activated sludge. Database 2015, bav062, doi:10.1093/database/bav062 (2015).

95 Houweling, D. et al. $\mathrm{N}_{2} \mathrm{O}$ emissions: modeling the effect of process configuration and diurnal loading patterns. Water Environ. Res. 83, 2131-2139 (2011).

96 Harris, E. et al. Isotopic evidence for nitrous oxide production pathways in a partial nitritation-anammox reactor. Water Res. 83, 258270, doi:10.1016/j.watres.2015.06.040 (2015).

97 Kampschreur, M. J. et al. Emission of nitrous oxide and nitric oxide from a full-scale single-stage nitritation-anammox reactor. Water Sci. Technol. 60, 3211-3217 (2009).

98 Schreiber, F., Wunderlin, P., Udert, K. M. \& Wells, G. F. Nitric oxide and nitrous oxide turnover in natural and engineered microbial communities: biological pathways, chemical reactions, and novel technologies. $\quad$ Front. Microbiol. 3, 372, doi:10.3389/fmicb.2012.00372 (2012).

99 Weissbrodt, D. G. et al. in IWA NRR 2015. (ed Oleszkiewicz et al.).

100 Sabba, F., Picioreanu, C., Perez, J. \& Nerenberg, R. Hydroxylamine diffusion can enhance $\mathrm{N}(2) \mathrm{O}$ emissions in nitrifying biofilms: a modeling study. Environ. Sci. Technol. 49, 1486-1494, doi:10.1021/es5046919 (2015).
101 Yoon, S., Song, B., Phillips, R. L., Chang, J. \& Song, M. J. Ecological and physiological implications of nitrogen oxide reduction pathways on greenhouse gas emissions in agroecosystems. FEMS Microbiol. Ecol. 95, doi:10.1093/femsec/fiz066 (2019).

102 Richardson, D., Felgate, H., Watmough, N., Thomson, A. \& Baggs, E. Mitigating release of the potent greenhouse gas $\mathrm{N}_{2} \mathrm{O}$ from the nitrogen cycle - could enzymic regulation hold the key? Trends Biotechnol. 27, 388-397 (2009).

103 Pijuan, M. et al. Effect of process parameters and operational mode on nitrous oxide emissions from a nitritation reactor treating reject wastewater. Water Res. 49, 23-33, doi:10.1016/j.watres.2013.11.009 (2014).

104 van Hulle, S. W. H., Callens, J., Mampaey, K. E., van Loosdrecht, M. C. M. \& Volcke, E. I. P. N2O and NO emissions during autotrophic nitrogen removal in a granular sludge reactor - A simulation study. Environ. Technol. 33, 2281-2290 (2012).

105 Sperandio, M. et al. Evaluation of different nitrous oxide production models with four continuous long-term wastewater treatment process data series. Bioprocess and biosystems engineering 39, 493-510, doi:10.1007/s00449-015-1532-2 (2016).

106 Nelson, D. H. The isolation of Nitrosomonas and Nitrobacter by the single cell technique. Science 71, 541-542, doi:10.1126/science.71.1847.541 (1930).

107 Kowalchuk, G. A. \& Stephen, J. R. Ammonia-oxidizing bacteria: a model for molecular microbial ecology. Annu. Rev. Microbiol. 55, 485-529, doi:10.1146/annurev.micro.55.1.485 (2001).

108 Jetten, M. S. M. et al. Microbiology and application of the anaerobic ammonium oxidation ('anammox') process. Curr. Opin. Biotechnol. 12, 283-288 (2001).

109 Lawson, C. E. et al. Autotrophic and mixotrophic metabolic network fluxes suggest versatile lifestyle for the anammox bacterium "Candidatus Kuenenia stuttgartiensis". bioRxiv, 835298, doi:10.1101/835298 (2019).

110 Gilbert, E. M., Muller, E., Horn, H. \& Lackner, S. Microbial activity of suspended biomass from a nitritation-anammox SBR in dependence of operational condition and size fraction. Appl. Microbiol. Biotechnol. 97, 8795-8804, doi:10.1007/s00253-012-4591-1 (2013).

111 Lotti, T., Kleerebezem, R., Lubello, C. \& van Loosdrecht, M. C. Physiological and kinetic characterization of a suspended cell anammox culture. Water Res. 60, 1-14, doi:10.1016/j.watres.2014.04.017 (2014).

112 Ganigué, R. et al. Long-term operation of a partial nitritation pilot plant treating leachate with extremely high ammonium concentration prior to an anammox process. Bioresour. Technol. 100, 5624-5632 (2009).

113 Kotay, S. M., Mansell, B. L., Hogsett, M., Pei, H. \& Goel, R. Anaerobic ammonia oxidation (ANAMMOX) for side-stream treatment of anaerobic digester filtrate process performance and microbiology. Biotechnol. Bioeng. 110, 1180-1192 (2013).

$114 \mathrm{Li}, \mathrm{X}$. R. et al. The bacterial diversity in an anaerobic ammoniumoxidizing (anammox) reactor community. Syst. Appl. Microbiol. 32, 278-289, doi:10.1016/j.syapm.2009.03.002 (2009).

115 Persson, F. et al. Structure and composition of biofilm communities in a moving bed biofilm reactor for nitritation-anammox at low temperatures. Bioresour. Technol. 154, 267-273, doi:10.1016/j.biortech.2013.12.062 (2014).

116 Almstrand, R., Daims, H., Persson, F., Sörensson, F. \& Hermansson, $\mathrm{M}$. New methods for analysis of spatial distribution and coaggregation of microbial populations in complex biofilms. Appl. Environ. Microbiol. 79, 5978-5987 (2013).

117 Almstrand, R. et al. Three-dimensional stratification of bacterial biofilm populations in a moving bed biofilm reactor for nitritationanammox. Int. J. Mol. Sci. 15, 2191-2206 (2014).

118 Bürgmann, H., Jenni, S., Vazquez, F. \& Udert, K. M. Regime shift and microbial dynamics in a sequencing batch reactor for nitrification and anammox treatment of urine. Appl. Environ. Microbiol. 77, 58975907, doi:10.1128/aem.02986-10 (2011).

119 Park, H. et al. Impact of inocula and growth mode on the molecular microbial ecology of anaerobic ammonia oxidation (anammox) bioreactor communities. Water Res. 44, 5005-5013 (2010).

120 Speth, D. R., in 't Zandt, M. H., Guerrero-Cruz, S., Dutilh, B. E. \& Jetten, M. S. M. Genome-based microbial ecology of anammox 
granules in a full-scale wastewater treatment system. Nat. Commun. 7, 11172, doi:10.1038/ncomms11172 (2016).

121 Weissbrodt, D. G., Schneiter, G. S., Fürbringer, J. M. \& Holliger, C. Identification of trigger factors selecting for polyphosphate- and glycogen-accumulating organisms in aerobic granular sludge sequencing batch reactors. Water Res. 47, 7006-7018, doi:10.1016/j.watres.2013.08.043 (2013).

122 Daran-Lapujade, P. et al. The fluxes through glycolytic enzymes in Saccharomyces cerevisiae are predominantly regulated at posttranscriptional levels. Proc. Natl. Acad. Sci. U. S. A. 104, 1575315758, doi:10.1073/pnas.0707476104 (2007).

123 Daran-Lapujade, P. et al. Role of transcriptional regulation in controlling fluxes in central carbon metabolism of Saccharomyces cerevisiae. A chemostat culture study. J. Biol. Chem. 279, 9125-9138, doi:10.1074/jbc.M309578200 (2004).

124 Hoelzle, R. D., Virdis, B. \& Batstone, D. J. Regulation mechanisms in mixed and pure culture microbial fermentation. Biotechnol. Bioeng. 111, 2139-2154, doi:10.1002/bit.25321 (2014).

125 Elias, S. \& Banin, E. Multi-species biofilms: living with friendly neighbors. FEMS Microbiol. Rev. 36, 990-1004, doi:10.1111/j.15746976.2012.00325.x (2012).

126 Wessels, H. J., de Almeida, N. M., Kartal, B. \& Keltjens, J. T. Bacterial Electron Transfer Chains Primed by Proteomics. Adv. Microb. Physiol. 68, 219-352, doi:10.1016/bs.ampbs.2016.02.006 (2016).

127 Hawley, A. K., Brewer, H. M., Norbeck, A. D., Pasa-Tolic, L. \& Hallam, S. J. Metaproteomics reveals differential modes of metabolic coupling among ubiquitous oxygen minimum zone microbes. Proc. Natl. Acad. Sci. U. S. A. 111, 11395-11400, doi:10.1073/pnas.1322132111 (2014).

128 Wilmes, P., Heintz-Buschart, A. \& Bond, P. L. A decade of metaproteomics: where we stand and what the future holds. Proteomics 15, 3409-3417, doi:10.1002/pmic.201500183 (2015).

129 Tyson, G. W. et al. Community structure and metabolism through reconstruction of microbial genomes from the environment. Nature 428, 37-43, doi:10.1038/nature02340 (2004).

130 Oldiges, M. \& Takors, R. Applying metabolic profiling techniques for stimulus-response experiments: chances and pitfalls. Adv. Biochem. Eng. Biotechnol. 92, 173-196 (2005).

131 Gabarró, J. et al. Nitrous oxide reduction genetic potential from the microbial community of an intermittently aerated partial nitritation SBR treating mature landfill leachate. Water Res. 47, 7066-7077 (2013).

132 Wu, S., Bhattacharjee, A. S., Weissbrodt, D. G., Morgenroth, E. \& Goel, R. Effect of short term external perturbations on bacterial ecology and activities in a partial nitritation and anammox reactor. Bioresour. Technol. 219, 527-535 (2016).

133 Bagchi, S., Lamendella, R., Strutt, S., van Loosdrecht, M. C. M. \& Saikaly, P. E. Metatranscriptomics reveals the molecular mechanism of large granule formation in granular anammox reactor. Sci. Rep. 6 , 28327, doi:10.1038/srep28327 (2016).

134 Park, H., Rosenthal, A., Ramalingam, K., Fillos, J. \& Chandran, K. Linking community profiles, gene expression and N-removal in anammox bioreactors treating municipal anaerobic digestion reject water. Environ. Sci. Technol. 44, 6110-6116 (2010).

135 Weissbrodt, D. G. et al. in 6th International Joint Specialist Conference on Microbial Ecology in Water Engineering \& Biofilms. (ed Smets et al.) (International Water Association).

136 Wang, Y. et al. Expression of the nirS, hzsA, and $h d h$ genes in response to nitrite shock and recovery in "Candidatus Kuenenia stuttgartiensis". Environ. Sci. Technol. 50, 6940-6947, doi:10.1021/acs.est.6b00546 (2016).

137 Verstraete, W. et al. Microbial Resource Management: The road to go for environmental biotechnology. Eng. Life Sci. 7, 117-126 (2007).

138 Rittmann, B. E. Microbial ecology to manage processes in environmental biotechnology. Trends Biotechnol. 24, 261-266 (2006).

139 Moralejo-Gárate, H., Mar'Atusalihat, E., Kleerebezem, R. \& Van Loosdrecht, M. C. M. Microbial community engineering for biopolymer production from glycerol. Appl. Microbiol. Biotechnol. 92, 631-639 (2011).

140 Kleerebezem, R. \& van Loosdrecht, M. C. Mixed culture biotechnology for bioenergy production. Curr. Opin. Biotechnol. 18, 207-212 (2007).
141 Weissbrodt, D. G. Engineering Granular Microbiomes. invited (Springer-Verlag GmbH, submitted).

142 Ofiteru, I. D. et al. Combined niche and neutral effects in a microbial wastewater treatment community. Proc. Natl. Acad. Sci. U. S. A. 107, 15345-15350 (2010).

143 Winkler, M. K. H., Kleerebezem, R. \& van Loosdrecht, M. C. M. Integration of anammox into the aerobic granular sludge process for main stream wastewater treatment at ambient temperatures. Water Res. 46, 136-144 (2012).

$144 \mathrm{Hu}, \mathrm{Z}$. et al. Nitrogen removal by a nitritation-anammox bioreactor at low temperature. Appl. Environ. Microbiol. 79, 2807-2812, doi:10.1128/aem.03987-12 (2013).

145 Langone, M. et al. Coexistence of nitrifying, anammox and denitrifying bacteria in a sequencing batch reactor. Front. Microbiol. 5, 28, doi:10.3389/fmicb.2014.00028 (2014).

146 Pellicer-Nacher, C. et al. Sequential aeration of membrane-aerated biofilm reactors for high-rate autotrophic nitrogen removal: Experimental demonstration. Environ. Sci. Technol. 44, 7628-7634 (2010).

147 Lotti, T. et al. Simultaneous partial nitritation and anammox at low temperature with granular sludge. Water Res. 66, 111-121, doi:10.1016/j.watres.2014.07.047 (2014)

148 Courtens, E. N. et al. Nitric oxide preferentially inhibits nitrite oxidizing communities with high affinity for nitrite. J. Biotechnol. 193, 120-122, doi:10.1016/j.jbiotec.2014.11.021 (2015).

149 Zekker, I. et al. Achieving nitritation and anammox enrichment in a single moving-bed biofilm reactor treating reject water. Environ. Technol. 33, 703-710 (2012).

150 Malovanyy, A., Yang, J., Trela, J. \& Plaza, E. Combination of upflow anaerobic sludge blanket (UASB) reactor and partial nitritation/anammox moving bed biofilm reactor (MBBR) for municipal wastewater treatment. Bioresour. Technol. 180, 144-153, doi:10.1016/j.biortech.2014.12.101 (2015).

$151 \mathrm{Ge}, \mathrm{S}$. et al. Detection of nitrifiers and evaluation of partial nitrification for wastewater treatment: A review. Chemosphere 140, 85-98, doi:10.1016/j.chemosphere.2015.02.004 (2015).

152 Malovanyy, A., Trela, J. \& Plaza, E. Mainstream wastewater treatment in integrated fixed film activated sludge (IFAS) reactor by partial nitritation/anammox process. Bioresour. Technol. 198, 478-487, doi:10.1016/j.biortech.2015.08.123 (2015).

153 Regmi, P. et al. Control of aeration, aerobic SRT and COD input for mainstream nitritation/denitritation. Water Res. 57, 162-171, doi:10.1016/j.watres.2014.03.035 (2014).

154 Han, M. et al. in Water Environment Federation's Annual Technical Exhibition and Conference (WEFTEC). (ed WEF).

155 Ma, Y., Sundar, S., Park, H. \& Chandran, K. The effect of inorganic carbon on microbial interactions in a biofilm nitritation-anammox process. Water Res. 70, 246-254, doi:10.1016/j.watres.2014.12.006 (2015).

156 Bagchi, S., Biswas, R. \& Nandy, T. Alkalinity and dissolved oxygen as controlling parameters for ammonia removal through partial nitritation and anammox in a single-stage bioreactor. J. Ind. Microbiol. Biotechnol. 37, 871-876 (2010).

$157 \mathrm{Xu}, \mathrm{G}$. et al. The challenges of mainstream deammonification process for municipal used water treatment. Appl. Microbiol. Biotechnol. 99, 2485-2490, doi:10.1007/s00253-015-6423-6 (2015).

158 Isanta, E., Reino, C., Carrera, J. \& Perez, J. Stable partial nitritation for low-strength wastewater at low temperature in an aerobic granular reactor. Water Res. 80, 149-158, doi:10.1016/j.watres.2015.04.028 (2015).

159 De Clippeleir, H. et al. in Water Environment Federation's Annual Technical Exhibition and Conference (WEFTEC). (ed WEF).

160 Chen, X., Guo, J., Xie, G. J., Yuan, Z. \& Ni, B. J. Achieving complete nitrogen removal by coupling nitritation-anammox and methanedependent denitrification: A model-based study. Biotechnol. Bioeng. 113, 1035-1045, doi:10.1002/bit.25866 (2015).

161 De Wit, R. \& Bouvier, T. 'Everything is everywhere, but, the environment selects'; what did Baas Becking and Beijerinck really say? Environ. Microbiol. 8, 755-758, doi:10.1111/j.14622920.2006.01017.x (2006). 
162 Widder, S. et al. Challenges in microbial ecology: building predictive understanding of community function and dynamics. ISME J. 10, 2557-2568, doi:10.1038/ismej.2016.45 (2016).

163 McMahon, K. D., Garcia Martin, H. \& Hugenholtz, P. Integrating ecology into biotechnology. Curr. Opin. Biotechnol. 18, 287-292 (2007).

164 Curtis, T. P. \& Sloan, W. T. Towards the design of diversity: Stochastic models for community assembly in wastewater treatment plants. Water Sci. Technol. 54, 227-236 (2006).

165 Curtis, T. P., Head, I. M. \& Graham, D. W. Theoretical Ecology for engineering biology. Environ. Sci. Technol. 37, 64A-70A (2003).

166 De Roy, K. et al. Environmental conditions and community evenness determine the outcome of biological invasion. Nat. Commun. 4, 1383, doi:10.1038/ncomms2392 (2013).

167 Szabo, E. et al. Microbial Population Dynamics and Ecosystem Functions of Anoxic/Aerobic Granular Sludge in Sequencing Batch Reactors Operated at Different Organic Loading Rates. Front. Microbiol. 8, 770, doi:10.3389/fmicb.2017.00770 (2017).

168 Johnson, D. R., Lee, T. K., Park, J., Fenner, K. \& Helbling, D. E. The functional and taxonomic richness of wastewater treatment plant microbial communities are associated with each other and with ambient nitrogen and carbon availability. Environ. Microbiol. 17, 4851-4860, doi:10.1111/1462-2920.12429 (2014).

169 Helbling, D. E., Johnson, D. R., Lee, T. K., Scheidegger, A. \& Fenner, K. A framework for establishing predictive relationships between specific bacterial $16 \mathrm{~S}$ rRNA sequence abundances and biotransformation rates. Water Res. 70, 471-484, doi:10.1016/j.watres.2014.12.013 (2015).

170 Ofiteru, I. D. \& Curtis, T. P. Modeling risk of failure in nitrification: Simple model incorporating abundance and diversity. J. Environ. Eng. 135, 660-665 (2009).

171 Zilles, J. L., Rodríguez, L. F., Bartolerio, N. A. \& Kent, A. D. Microbial community modeling using reliability theory. ISME J. 10, 1809-1814 (2016).

172 Schmid, M. et al. Molecular evidence for genus level diversity of bacteria capable of catalyzing anaerobic ammonium oxidation. Syst. Appl. Microbiol. 23, 93-106 (2000).

173 Third, K. A., Sliekers, A. O., Kuenen, J. G. \& Jetten, M. S. M. The CANON system (completely autotrophic nitrogen-removal over nitrite) under ammonium limitation: Interaction and competition between three groups of bacteria. Syst. Appl. Microbiol. 24, 588-596 (2001)

174 Lopez, H. et al. Start-up and enrichment of a granular anammox SBR to treat high nitrogen load wastewaters. J. Chem. Technol. Biotechnol. 83, 233-241 (2008).

175 Desloover, J. et al. Floc-based sequential partial nitritation and anammox at full scale with contrasting $\mathrm{N} 2 \mathrm{O}$ emissions. Water Res. $\mathbf{4 5}$, 2811-2821, doi:10.1016/j.watres.2011.02.028 (2011).

176 (!!! INVALID CITATION !!! 89).

177 Junier, P. et al. Phylogenetic and functional marker genes to study ammonia-oxidizing microorganisms (AOM) in the environment. Appl. Microbiol. Biotechnol. 85, 425-440, doi:10.1007/s00253-009-2228-9 (2010).

178 Stahl, D. A. \& de la Torre, J. R. Physiology and diversity of ammoniaoxidizing archaea. Annu. Rev. Microbiol. 66, 83-101, doi:10.1146/annurev-micro-092611-150128 (2012).

179 Gonzalez-Martinez, A. et al. Archaeal populations in full-scale autotrophic nitrogen removal bioreactors operated with different technologies: CANON, DEMON and partial nitritation/anammox. Chem. Eng. J. 277, 194-201, doi:10.1016/j.cej.2015.04.137 (2015)

180 Langone, M. Simultaneous Partial Nitritation, Anammox and Denitrification (SNAD) Process for Treating Ammonium-Rich Wastewater, University of Trento, (2013).

181 Fitzgerald, C. M., Camejo, P., Oshlag, J. Z. \& Noguera, D. R. Ammonia-oxidizing microbial communities in reactors with efficient nitrification at low-dissolved oxygen. Water Res. 70, 38-51, doi:10.1016/j.watres.2014.11.041 (2015).

182 van Kessel, M. A. et al. Complete nitrification by a single microorganism. Nature 528, 555-559, doi:10.1038/nature16459 (2015).

183 Sorokin, D. Y. et al. Nitrification expanded: discovery, physiology and genomics of a nitrite-oxidizing bacterium from the phylum
Chloroflexi. ISME J. 6, 2245-2256, doi:10.1038/ismej.2012.70 (2012).

184 Nielsen, P. H. \& McMahon, K. D. Microbiology and microbial ecology of the activated sludge process. in Activated Sludge - 100 Years and Counting (eds D. Jenkins \& J. Wanner) 464 (IWA Publishing, 2014).

185 Cloete, T. E. \& Muyima, N. Y. O. Microbial community analysis: The key to the design of wastewater treatment systems. (IWA Publishing, 1997).

186 Mozumder, M. S. I., Picioreanu, C., van Loosdrecht, M. C. M. \& Volcke, E. I. P. Effect of heterotrophic growth on autotrophic nitrogen removal in a granular sludge reactor. Environ. Technol. 35, 1027-1037 (2014).

187 Jimenez, J. et al. High-rate activated sludge system for carbon management - Evaluation of crucial process mechanisms and design parameters. Water $\quad$ Res. 87, 476-482, doi:10.1016/j.watres.2015.07.032 (2015)

188 Nielsen, P. H., Thomsen, T. R. \& Nielsen, J. L. Bacterial composition of activated sludge - Importance for floc and sludge properties. Water Sci. Technol. 49, 51-58 (2004).

189 Laspidou, C. S. \& Rittmann, B. E. Modeling the development of biofilm density including active bacteria, inert biomass, and extracellular polymeric substances. Water Res. 38, 3349-3361 (2004).

190 Pellicer-Nàcher, C., Domingo-Félez, C., Mutlu, A. G. \& Smets, B. F. Critical assessment of extracellular polymeric substances extraction methods from mixed culture biomass. Water Res. 47, 5564-5574 (2013).

191 Alpkvist, E., Picioreanu, C., van Loosdrecht, M. C. M. \& Heyden, A. Three-dimensional biofilm model with individual cells and continuum EPS matrix. Biotechnol. Bioeng. 94, 961-979 (2006).

192 Wang, Y., Hu, X., Jiang, B., Song, Z. \& Ma, Y. Symbiotic relationship analysis of predominant bacteria in a lab-scale anammox UASB bioreactor. Environ. Sci. Pollut R. 23, 7615-7626, doi:10.1007/s11356-015-6016-z (2016).

193 Miura, Y., Watanabe, Y. \& Okabe, S. Significance of Chloroflexi in performance of submerged membrane bioreactors (MBR) treating municipal wastewater. Environ. Sci. Technol. 41, 7787-7794, doi:10.1021/es071263x (2007).

194 Kindaichi, T., Yuri, S., Ozaki, N. \& Ohashi, A. Ecophysiological role and function of uncultured Chloroflexi in an anammox reactor. Water Sci. Technol. 66, 2556-2561, doi:10.2166/wst.2012.479 (2012).

195 Noguera, D. R., Araki, N. \& Rittmann, B. E. Soluble microbial products (SMP) in anaerobic chemostats. Biotechnol. Bioeng. 44 1040-1047, doi:10.1002/bit.260440904 (1994).

196 Ni, B.-J., Rittmann, B. E. \& Yu, H.-Q. Soluble microbial products and their implications in mixed culture biotechnology. Trends Biotechnol. 29, 454-463, doi:10.1016/j.tibtech.2011.04.006.

197 Shapiro, O. H. \& Kushmaro, A. Bacteriophage ecology in environmental biotechnology processes. Curr. Opin. Biotechnol. 22, 449-455 (2011).

198 Rodriguez-Valera, F. et al. Explaining microbial population genomics through phage predation. Nat Rev Micro 7, 828-836, doi:10.1038/nrmicro2235 (2009).

199 Johnke, J. et al. Multiple micro-predators controlling bacterial communities in the environment. Curr. Opin. Biotechnol. 27, 185-190, doi:10.1016/j.copbio.2014.02.003 (2014).

200 Ormala-Odegrip, A. M. et al. Protist predation can select for bacteria with lowered susceptibility to infection by lytic phages. BMC Evol. Biol. 15, 81, doi:10.1186/s12862-015-0341-1 (2015).

201 Motlagh, A. M., Bhattacharjee, A. S. \& Goel, R. Microbiological study of bacteriophage induction in the presence of chemical stress factors in enhanced biological phosphorus removal (EBPR). Water Res. 81, 1-14, doi:10.1016/j.watres.2015.04.023 (2015).

202 Klein, T. et al. Biological control of biofilms on membranes by metazoans. Water Res. 88, 20-29 (2016).

203 Barr, J. J., Slater, F. R., Fukushima, T. \& Bond, P. L. Evidence for bacteriophage activity causing community and performance changes in a phosphorus-removal activated sludge. FEMS Microbiol. Ecol. $\mathbf{7 4}$ 631-642 (2010).

204 Weinbauer, M. G. \& Rassoulzadegan, F. Are viruses driving microbial diversification and diversity? Environ. Microbiol. 6, 1-11 (2004). 
205 Suarez, C., Persson, F. \& Hermansson, M. Predation of nitritationanammox biofilms used for nitrogen removal from wastewater. FEMS Microbiol. Ecol. 91, fiv124, doi:10.1093/femsec/fiv124 (2015).

206 Kucnerowicz, F. \& Verstraete, W. Evolution of microbial communities in the activated sludge process. Water Res. 17, 12751279 (1983).

207 Vlaeminck, S. E. et al. Nitrogen removal from digested black water by one-stage partial nitritation and anammox. Environ. Sci. Technol. 43, 5035-5041 (2009).

208 Cema, G., Zabczynski, S. \& Ziembinska-Buczynska, A. The assessment of the coke wastewater treatment efficacy in rotating biological contractor. Water Sci. Technol. 73, 1202-1210, doi:10.2166/wst.2015.594 (2016).

209 Weissbrodt, D. G. et al. in Water Environment Federation's Annual Technical Exhibition and Conference. (ed WEF) (Water Environment Federation).

210 Orschler, L., Agrawal, S. \& Lackner, S. On resolving ambiguities in microbial community analysis of partial nitritation anammox reactors. Sci. Rep. 9, 6954, doi:10.1038/s41598-019-42882-8 (2019).

211 Dueholm, M. S. et al. Comprehensive ecosystem-specific 16S rRNA gene databases with automated taxonomy assignment (AutoTax) provide species-level resolution in microbial ecology. bioRxiv, 672873, doi:10.1101/672873 (2019).

212 de los Reyes, F. L., 3rd, Weaver, J. E. \& Wang, L. A methodological framework for linking bioreactor function to microbial communities and environmental conditions. Curr. Opin. Biotechnol. 33, 112-118, doi:10.1016/j.copbio.2015.02.002 (2015).

213 Pronk, M., Abbas, B., Kleerebezem, R. \& van Loosdrecht, M. C. Effect of sludge age on methanogenic and glycogen accumulating organisms in an aerobic granular sludge process fed with methanol and acetate. Microb. Biotechnol. 8, 853-864, doi:10.1111/17517915.12292 (2015)

214 Albertsen, M., Karst, S. M., Ziegler, A. S., Kirkegaard, R. H. \& Nielsen, P. H. Back to Basics--The influence of DNA extraction and primer choice on phylogenetic analysis of activated sludge communities. PLoS One 10, e0132783, doi:10.1371/journal.pone.0132783 (2015).

215 Ashelford, K. E., Chuzhanova, N. A., Fry, J. C., Jones, A. J. \& Weightman, A. J. At least 1 in 20 16S rRNA sequence records currently held in public repositories is estimated to contain substantial anomalies. Appl. Environ. Microbiol. 71, 7724-7736, doi:10.1128/aem.71.12.7724-7736.2005 (2005).

216 Birtel, J., Walser, J. C., Pichon, S., Burgmann, H. \& Matthews, B. Estimating bacterial diversity for ecological studies: methods, metrics, and assumptions. PLoS One 10, e0125356, doi:10.1371/journal.pone.0125356 (2015).

217 Meola, M., Lazzaro, A. \& Zeyer, J. Diversity, resistance, and resilience of the bacterial communities at two alpine glacier forefields after a reciprocal soil transplantation. Environ. Microbiol. 16, 19181934, doi:10.1111/1462-2920.12435 (2014).

218 Sinclair, L., Osman, O. A., Bertilsson, S. \& Eiler, A. Microbial community composition and diversity via $16 \mathrm{~S}$ rRNA gene amplicons: evaluating the illumina platform. PLoS One 10, e0116955, doi:10.1371/journal.pone.0116955 (2015).

219 Sun, Y., Wolcott, R. D. \& Dowd, S. E. Tag-Encoded FLX Amplicon Pyrosequencing for the Elucidation of Microbial and Functional Gene Diversity in Any Environment. Methods Mol. Biol. 733, 129-141, doi:10.1007/978-1-61779-089-8_9(2011).

220 Weissbrodt, D. G. et al. PyroTRF-ID: a novel bioinformatics methodology for the affiliation of terminal-restriction fragments using 16S rRNA gene pyrosequencing data. BMC Microbiol. 12, 306, doi:10.1186/1471-2180-12-306 (2012).

221 Pinto, A. J. \& Raskin, L. PCR biases distort bacterial and archaeal community structure in pyrosequencing datasets. PLoS One 7, e43093, doi:10.1371/journal.pone.0043093 (2012).

222 Winkler, M. K. H. et al. An integrative review of granular sludge for the biological removal of nutrients and of recalcitrant organic matter from wastewater. Chem. Eng. J. 336, 489-502 (2018).

223 Weissbrodt, D. G., Laureni, M., van Loosdrecht, M. C. M. \& Comeau, Y. Basic Microbiology and Metabolism. in Biological Wastewater Treatment: Principles, Modelling and Design (eds G. H. Chen, M. C. M. van Loosdrecht, G. A. Ekama, \& D. Brdjanovic) Ch. 2, (IWA Publishing, 2020).
224 Karst, S. M., Albertsen, M., Kirkegaard, R. H., Dueholm, M. S. \& Nielsen, P. H. Molecular methods. in Experimental Methods in Wastewater Treatment (eds M. C. M. van Loosdrecht, P. H. Nielsen, C. M. Lopez-Vazquez, \& D. Brdjanovic) 285-323 (IWA Publishing, 2016).

225 Nielsen, J. L., Seviour, R. J. \& Nielsen, P. H. Microscopy. in Experimental Methods in Wastewater Treatment (eds M. C. M. van Loosdrecht, P. H. Nielsen, C. M. Lopez-Vazquez, \& D. Brdjanovic) 263-284 (IWA Publishing, 2016).

226 Schmid, M. C. et al. Biomarkers for in situ detection of anaerobic ammonium-oxidizing (Anammox) bacteria. Appl. Environ. Microbiol. 71, 1677-1684 (2005).

227 Zwirglmaier, K., Ludwig, W. \& Schleifer, K. H. Recognition of individual genes in a single bacterial cell by fluorescence in situ hybridization--RING-FISH. Mol. Microbiol. 51, 89-96 (2004).

228 Pratscher, J., Stichternoth, C., Fichtl, K., Schleifer, K.-H. \& Braker, G. Application of Recognition of Individual Genes-Fluorescence In Situ Hybridization (RING-FISH) To Detect Nitrite Reductase Genes (nirK) of Denitrifiers in Pure Cultures and Environmental Samples. Appl. Environ. Microbiol. 75, 802-810, doi:10.1128/aem.01992-08 (2009).

229 Nierychlo, M. et al. Species-level microbiome composition of activated sludge - introducing the MiDAS 3 ecosystem-specific reference database and taxonomy. bioRxiv, 842393 , doi:10.1101/842393 (2019).

230 Noguera, D. R., Wright, E. S., Camejo, P. \& Yilmaz, L. S. Mathematical tools to optimize the design of oligonucleotide probes and primers. Appl. Microbiol. Biotechnol. 98, 9595-9608, doi:10.1007/s00253-014-6165-x (2014).

231 Klindworth, A. et al. Evaluation of general 16S ribosomal RNA gene PCR primers for classical and next-generation sequencing-based diversity studies. Nucleic Acids Res. 41, e1, doi:10.1093/nar/gks808 (2013).

232 Pruesse, E. et al. SILVA: a comprehensive online resource for quality checked and aligned ribosomal RNA sequence data compatible with ARB. Nucleic Acids Res. 35, 7188-7196 (2007).

233 Wagner, M. Crystal ball. The community level: physiology and interactions of prokaryotes in the wilderness. Environ. Microbiol. 7, 483-485 (2005).

234 Musat, N., Foster, R., Vagner, T., Adam, B. \& Kuypers, M. M. M. Detecting metabolic activities in single cells, with emphasis on nanoSIMS. FEMS Microbiol. Rev. 36, 486-511, doi:doi:10.1111/j.1574-6976.2011.00303.x (2012).

235 Wagner, M. \& Haider, S. New trends in fluorescence in situ hybridization for identification and functional analyses of microbes. Curr. Opin. Biotechnol. 23, 96-102 (2012).

236 Collins, G. et al. Accessing the black box of microbial diversity and ecophysiology: recent advances through polyphasic experiments. $J$. Environ. Sci. Health A Tox. Hazard. Subst. Environ. Eng. 41, 897-922, doi:10.1080/10934520600614546 (2006).

237 Nielsen, J. L., Christensen, D., Kloppenborg, M. \& Nielsen, P. H. Quantification of cell-specific substrate uptake by probe-defined bacteria under in situ conditions by microautoradiography and fluorescence in situ hybridization. Environ. Microbiol. 5, 202-211 (2003).

238 Kartal, B. et al. Anammox bacteria disguised as denitrifiers: Nitrate reduction to dinitrogen gas via nitrite and ammonium. Environ. Microbiol. 9, 635-642 (2007).

239 Hatzenpichler, R. et al. In situ visualization of newly synthesized proteins in environmental microbes using amino acid tagging and click chemistry. Environ. Microbiol. 16, 2568-2590, doi:10.1111/1462-2920.12436 (2014).

240 Landgraf, P., Antileo, E. R., Schuman, E. M. \& Dieterich, D. C. BONCAT: metabolic labeling, click chemistry, and affinity purification of newly synthesized proteomes. Methods Mol. Biol. 1266, 199-215, doi:10.1007/978-1-4939-2272-7_14 (2015).

241 McIlroy, S. J. et al. Identification of active denitrifiers in full-scale nutrient removal wastewater treatment systems. Environ. Microbiol. 18, 50-64, doi:10.1111/1462-2920.12614 (2014).

242 Nielsen, J. L., Nguyen, H., Meyer, R. L. \& Nielsen, P. H. Identification of glucose-fermenting bacteria in a full-scale enhanced biological phosphorus removal plant by stable isotope probing. Microbiology 158, 1818-1825, doi:10.1099/mic.0.058818-0 (2012). 
243 Dumont, M. G. \& Murrell, J. C. Stable isotope probing - linking microbial identity to function. Nat. Rev. Microbiol. 3, 499-504 (2005).

244 Neufeld, J. D. et al. DNA stable-isotope probing. Nat. Protoc. 2, 860866, doi:10.1038/nprot.2007.109 (2007).

245 Mcllroy, S. J. et al. Characterization of the in situ ecophysiology of novel phylotypes in nutrient removal activated sludge treatment plants. PLoS One 10, e0136424, doi:10.1371/journal.pone.0136424 (2015).

246 Musat, N., Foster, R., Vagner, T., Adam, B. \& Kuypers, M. M. Detecting metabolic activities in single cells, with emphasis on nanoSIMS. FEMS Microbiol. Rev. 36, 486-511, doi:10.1111/j.15746976.2011.00303.x (2012).

247 Gülay, A. et al. DNA- and RNA-SIP Reveal Nitrospira spp. as Key Drivers of Nitrification in Groundwater-Fed Biofilters. mBio 10, e01870-01819, doi:10.1128/mBio.01870-19 (2019).

248 Gao, D., Huang, X. \& Tao, Y. A critical review of NanoSIMS in analysis of microbial metabolic activities at single-cell level. Crit. Rev. Biotechnol., 1-7, doi:10.3109/07388551.2015.1057550 (2015).

249 Tyson, G. W. \& Banfield, J. F. Cultivating the uncultivated: a community genomics perspective. Trends Microbiol. 13, 411-415, doi:10.1016/j.tim.2005.07.003 (2005).

250 Gori, F. et al. Differences in sequencing technologies improve the retrieval of anammox bacterial genome from metagenomes. $B M C$ Genomics 14, 7, doi:10.1186/1471-2164-14-7 (2013).

251 Rodriguez-Ezpeleta, N., Hackenberg, M. \& Aransay, A. M. Bioinformatics for High Throughput Sequencing. (Springer, 2012).

252 Daims, H. et al. Complete nitrification by Nitrospira bacteria. Nature, doi:10.1038/nature16461 (2015).

253 Koch, H. et al. Expanded metabolic versatility of ubiquitous nitriteoxidizing bacteria from the genus Nitrospira. Proc. Natl. Acad. Sci. U. S. A. 112, 11371-11376, doi:10.1073/pnas.1506533112 (2015).

254 Niedenfuhr, S. et al. Natural isotope correction of MS/MS measurements for metabolomics and C fluxomics. Biotechnol. Bioeng. 113, 1137-1147, doi:10.1002/bit.25859 (2015).

$255 \mathrm{Li}$, J. et al. Quantify the contribution of anammox for enhanced nitrogen removal through metagenomic analysis and mass balance in an anoxic moving bed biofilm reactor. Water Res. 160, 178-187, doi:10.1016/j.watres.2019.05.070 (2019).

256 Skennerton, C. T., Barr, J. J., Slater, F. R., Bond, P. L. \& Tyson, G. W. Expanding our view of genomic diversity in "Candidatus Accumulibacter" clades. Environ. Microbiol. 17, 1574-1585, doi:10.1111/1462-2920.12582 (2015).

257 Wilmes, P. et al. Community proteogenomics highlights microbial strain-variant protein expression within activated sludge performing enhanced biological phosphorus removal. ISME J. 2, 853-864 (2008).

258 Barr, J. J. et al. Metagenomic and metaproteomic analyses of Accumulibacter phosphatis-enriched floccular and granular biofilm. Environ. Microbiol. 18, 273-287, doi:10.1111/1462-2920.13019 (2015).

259 Oyserman, B. O., Noguera, D. R., Del Rio, T. G., Tringe, S. G. \& McMahon, K. D. Metatranscriptomic insights on gene expression and regulatory controls in Candidatus Accumulibacter phosphatis. ISME $J$. 10, 810-822, doi:10.1038/ismej.2015.155 (2016).

260 Albertsen, M., Hansen, L. B. S., Saunders, A. M., Nielsen, P. H. \& Nielsen, K. L. A metagenome of a full-scale microbial community carrying out enhanced biological phosphorus removal. ISME J. 6, 1094-1106 (2012).

261 Garcia Martin, H. et al. Metagenomic analysis of two enhanced biological phosphorus removal (EBPR) sludge communities. Nat. Biotechnol. 24, 1263-1269 (2006).

262 Rodríguez, E., García-Encina, P., Stams, A. M., Maphosa, F. \& Sousa, D. Meta-omics approaches to understand and improve wastewater treatment systems. Rev. Environ. Sci. Bio. 14, 385-406, doi:10.1007/s11157-015-9370-x (2015).

263 Johnson, D. R., Helbling, D. E., Men, Y. \& Fenner, K. Can metaomics help to establish causality between contaminant biotransformations and genes or gene products? Environmental science : water research \& technology 1, 272-278, doi:10.1039/c5ew00016e (2015).

264 Park, H., Murthy, S., Bott, C., van Loosdrecht, M. C. M. \& Chandran, K. in Water Environment Federation's Annual Technical Exhibition and Conference (WEFTEC). (ed WEF).
265 Lawson, C. E. et al. in Water Environment Federation's Annual Technical Exhibition and Conference (WEFTEC). (ed WEF) (Water Environment Federation).

266 Strous, M. et al. Deciphering the evolution and metabolism of an anammox bacterium from a community genome. Nature 440, 790-794 (2006).

267 Klotz, M. G. \& Stein, L. Y. Nitrifier genomics and evolution of the nitrogen cycle. FEMS Microbiol. Lett. 278, 146-156, doi:10.1111/j.1574-6968.2007.00970.x (2008).

268 van de Vossenberg, J. et al. The metagenome of the marine anammox bacterium "Candidatus Scalindua profunda" illustrates the versatility of this globally important nitrogen cycle bacterium. Environ. Microbiol. 15, 1275-1289, doi:10.1111/j.1462-2920.2012.02774.x (2013).

269 Speth, D. R. et al. Comparative genomics of two independently enriched "Candidatus Kuenenia stuttgartiensis" anammox bacteria. Front. Microbiol. 3, 307, doi:10.3389/fmicb.2012.00307 (2012).

270 Goel, R., Kotay, S. M., Butler, C. S., Torres, C. I. \& Mahendra, S. Molecular biological methods in environmental engineering. Water Environ. Res. 83, 927-955 (2011).

271 Besmer, M. D. et al. The feasibility of automated online flow cytometry for in-situ monitoring of microbial dynamics in aquatic ecosystems. Front. Microbiol. 5, 265, doi:10.3389/fmicb.2014.00265 (2014).

272 Zhao, J. et al. GeoChip-based analysis of microbial community of a combined nitritation-anammox reactor treating anaerobic digestion $\begin{array}{llll}\text { supernatant. Water } & \text { Res. 67, 345-354, }\end{array}$ doi:10.1016/j.watres.2014.09.029 (2014).

273 Nielsen, P. H. et al. A conceptual ecosystem model of microbial communities in enhanced biological phosphorus removal plants. Water Res. 44, 5070-5088 (2010).

274 Weissbrodt, D. G. et al. in Water Environment Federation's Annual Technical Exhibition and Conference (WEFTEC). (ed WEF) (Water Environment Federation).

275 Graham, D. W. \& Smith, V. H. Designed ecosystem services: application of ecological principles in wastewater treatment engineering. Front. Ecol. Environ. 2, 199-206, doi:10.1890/15409295(2004)002[0199:DESAOE]2.0.CO;2 (2004).

276 Anonymous. Crystal ball - 2011. Microb. Biotechnol. 4, 109-137, doi:10.1111/j.1751-7915.2010.00245.x (2011).

277 Johnson, D. R., Goldschmidt, F., Lilja, E. E. \& Ackermann, M. Metabolic specialization and the assembly of microbial communities. ISME J. 6, 1985-1991, doi:10.1038/ismej.2012.46 (2012).

278 Lindemann, S. R. et al. Engineering microbial consortia for controllable outputs. ISME J. 10, 2077-2084, doi:10.1038/ismej.2016.26 (2016).

279 Buckley, M. R. Systems Microbiology: Beyong Microbial Genomics. 20 (American Academy of Microbiology, Washington D. C., USA, 2004).

280 Ideker, T., Galitski, T. \& Hood, L. A new approach to decoding life: systems biology. Annual review of genomics and human genetics 2, 343-372, doi:10.1146/annurev.genom.2.1.343 (2001).

281 Weissbrodt, D. G., Winkler, M. K. H. \& Wells, G. F. Responsible Science, Engineering and Education for Water Resource Recovery and Circularity. ChemRxiv Preprint, 12218450, doi:10.26434/chemrxiv.12218450.v1 (2020).

282 Edwards, R. A. The smallest cells pose the biggest problems: Highperformance computing and the analysis of metagenome sequence data. J. Phys. Conf. Ser. 125, 012050 (2008).

283 Sboner, A., Mu, X. J., Greenbaum, D., Auerbach, R. K. \& Gerstein, $\mathrm{M}$. B. The real cost of sequencing: higher than you think! Genome Biol. 12, 125, doi:10.1186/gb-2011-12-8-125 (2011).

284 Borcard, D., Gillet, F. \& Legendre, P. Numerical Ecology with R. 1st edn, 306 (Springer-Verlag GmbH, 2011).

285 Buttigieg, P. L. \& Ramette, A. A guide to statistical analysis in microbial ecology: a community-focused, living review of multivariate data analyses. FEMS Microbiol. Ecol. 90, 543-550, doi:10.1111/1574-6941.12437 (2014).

286 Andersen, K. S., Kirkegaard, R. H., Karst, S. M. \& Albertsen, M. ampvis2: an R package to analyse and visualise 16S rRNA amplicon data. bioRxiv, 299537, doi:10.1101/299537 (2018). 
287 de Jonge, N., Moset, V., Moller, H. B. \& Nielsen, J. L. Microbial population dynamics in continuous anaerobic digester systems during start up, stable conditions and recovery after starvation. Bioresour. Technol. 232, 313-320, doi:10.1016/j.biortech.2017.02.036 (2017).

288 Law, Y. et al. Integrative microbial community analysis reveals fullscale enhanced biological phosphorus removal under tropical conditions. Sci. Rep. 6, 25719, doi:10.1038/srep25719 (2016).

289 Wells, G. F. et al. Comparing the Resistance, Resilience, and Stability of Replicate Moving Bed Biofilm and Suspended Growth Combined Nitritation-Anammox Reactors. Environ. Sci. Technol. 51, 5108-5117, doi:10.1021/acs.est.6b05878 (2017).

290 Winkler, M. K. et al. Microbial diversity differences within aerobic granular sludge and activated sludge flocs. Appl. Microbiol. Biotechnol., 1-12, doi:10.1007/s00253-012-4472-7 (2012).

291 Leventhal, G. E. et al. Strain-level diversity drives alternative community types in millimetre-scale granular biofilms. Nat Microbiol 3, 1295-1303, doi:10.1038/s41564-018-0242-3 (2018).

292 Neu, T. R. \& Lawrence, J. R. Development and structure of microbial biofilms in river water studied by confocal laser scanning microscopy. FEMS Microbiol. Ecol. 24, 11-25 (1997).

293 Neu, T. R. \& Kuhlicke, U. Fluorescence Lectin Bar-Coding of Glycoconjugates in the Extracellular Matrix of Biofilm and Bioaggregate Forming Microorganisms. Microorganisms 5, doi:10.3390/microorganisms5010005 (2017).

294 Okabe, S., Satoh, H. \& Watanabe, Y. In situ analysis of nitrifying biofilms as determined by in situ hybridization and the use of microelectrodes. Appl. Environ. Microbiol. 65, 3182-3191 (1999).

295 Kuhl, M. \& Jorgensen, B. B. Microsensor measurements of sulfate reduction and sulfide oxidation in compact microbial communities of aerobic biofilms. Appl. Environ. Microbiol. 58, 1164-1174 (1992).

296 Herbst, F. A. et al. Enhancing Metaproteomics - The value of models and defined environmental microbial systems. Proteomics 16, 783798, doi:10.1002/pmic.201500305 (2015).

297 Verstraete, W. The technological side of the microbiome. Npj Biofilms and Microbiomes 1, 15001, doi:10.1038/npjbiofilms.2015.1 (2015).

298 Lawson, C. E. et al. Rare taxa have potential to make metabolic contributions in enhanced biological phosphorus removal ecosystems. Environ. Microbiol. 17, 4979-4993, doi:10.1111/1462-2920.12875 (2015).

299 Rubio-Rincon, F. J. et al. "Candidatus Accumulibacter delftensis": A clade IC novel polyphosphate-accumulating organism without denitrifying activity on nitrate. Water Res. 161, 136-151, doi:10.1016/j.watres.2019.03.053 (2019).

$300 \mathrm{Gao}, \mathrm{H}$. et al. Genome-centric metagenomics resolves microbial diversity and prevalent truncated denitrification pathways in a denitrifying PAO-enriched bioprocess. Water Res. 155, 275-287, doi:10.1016/j.watres.2019.02.020 (2019).

301 da Silva, L. G. et al. Revealing metabolic flexibility of "Candidatus Accumulibacter phosphatis" through redox cofactor analysis and metabolic network modeling. bioRxiv, 458331, doi:10.1101/458331 (2018).
302 Magnusdottir, S. et al. Generation of genome-scale metabolic reconstructions for 773 members of the human gut microbiota. Nat. Biotechnol. 35, doi:10.1038/nbt.3703 (2017).

303 Hanson, N. W. et al. Metabolic pathways for the whole community. BMC Genomics 15, 619, doi:10.1186/1471-2164-15-619 (2014).

304 Nielsen, J. L., Kragelund, C. \& Nielsen, P. H. Ecophysiological analysis of microorganisms in complex microbial systems by combination of fluorescence in situ hybridization with extracellular staining techniques. Methods in molecular biology (Clifton, N.J.) 599, 117-128 (2010).

305 Daims, H. et al. in Water Sci. Technol. Vol. 54 21-27 (2006).

306 Tao, Y. et al. NanoSIMS reveals unusual enrichment of acetate and propionate by an anammox consortium dominated by Jettenia asiatica. Water Res. 159, 223-232, doi:10.1016/j.watres.2019.05.006 (2019).

307 Dalsgaard, T. et al. Oxygen at nanomolar levels reversibly suppresses process rates and gene expression in anammox and denitrification in the oxygen minimum zone off Northern Chile. mBio 5, doi:10.1128/mBio.01966-14 (2014).

308 Helbling, D. E., Ackermann, M., Fenner, K., Kohler, H. P. \& Johnson, D. R. The activity level of a microbial community function can be predicted from its metatranscriptome. ISME J. 6, 902-904, doi:10.1038/ismej.2011.158 (2012).

309 Narayanasamy, S., Muller, E. E., Sheik, A. R. \& Wilmes, P. Integrated omics for the identification of key functionalities in biological wastewater treatment microbial communities. Microb. Biotechnol. 8, 363-368, doi:10.1111/1751-7915.12255 (2015).

310 Crovadore, J. et al. Metatranscriptomic and metagenomic description of the bacterial nitrogen metabolism in waste water wet oxidation effluents. Heliyon 3, e00427, doi:10.1016/j.heliyon.2017.e00427 (2017).

311 Crovadore, J. et al. Metagenomes and Metatranscriptomes of Activated Sludge from a Sewage Plant, with or without Aerobic Granule Enrichment. Genome announcements 5, doi:10.1128/genomeA.00372-17 (2017).

312 Sato, Y. et al. Transcriptome analysis of activated sludge microbiomes reveals an unexpected role of minority nitrifiers in carbon metabolism. Commun Biol 2, 179, doi:10.1038/s42003-019-0418-2 (2019).

313 Yu, K. \& Zhang, T. Metagenomic and metatranscriptomic analysis of microbial community structure and gene expression of activated sludge. PLoS One 7, e38183, doi:10.1371/journal.pone.0038183 (2012).

314 Herbst, F.-A. et al. Enhancing metaproteomics-The value of models and defined environmental microbial systems. Proteomics 16, 783798, doi:10.1002/pmic.201500305 (2016).

315 Schumacher, R. \& Wahl, S. A. Effective Estimation of Dynamic Metabolic Fluxes Using (13)C Labeling and Piecewise Affine Approximation: From Theory to Practical Applicability. Metabolites 5, 697-719, doi:10.3390/metabo5040697 (2015).

316 Buchholz, A., Hurlebaus, J., Wandrey, C. \& Takors, R. Metabolomics: quantification of intracellular metabolite dynamics. Biomolecular engineering 19, 5-15 (2002). 